\title{
Anthropogenic Noise and the Endangered Cook Inlet Beluga Whale, Delphinapterus leucas: Acoustic Considerations for Management
}

\author{
MANUEL CASTELLOTE, BRUCE THAYRE, MICHAEL MAHONEY, JEFFREY MONDRAGON, \\ MARC O. LAMMERS, and ROBERT J. SMALL
}

\section{Introduction}

Cook Inlet belugas, Delphinapterus leucas, are a small, geographically and genetically isolated population with strong site fidelity, making them particularly vulnerable to anthropogenic impacts (Hobbs et al. ${ }^{1}$ ). This popula-

${ }^{1}$ Hobbs, R. C., K. E. W. Shelden, D. J. Vos, K. and extinction assessment of Cook Inlet belu-

Manuel Castellote is with the Joint Institute for the Study of the Atmosphere and Ocean (JISAO), University of Washington and Marine Mammal Laboratory, Alaska Fisheries Science Center, National Marine Fisheries Service, NOAA, 7600 Sand Point Way N.E., Seattle, WA 98115 (email: manuel.castellote@noaa. gov). Bruce Thayre is with Scripps Institution of Oceanography, University of California San Diego, 8622 Kennel Way, La Jolla, CA 92037. Michael Mahoney is with Mt. Edgecumbe High School, 1330 Seward Ave., Sitka, AK 99835. Marc O. Lammers is with Oceanwide Science Institute, P.O. Box 61692, Honolulu, HI 96839. Jeffrey Mondragon and Robert J. Small are with the Alaska Department of Fish and Game, 1255 W. 8th Street, Juneau, AK 99811.

doi: https://doi.org/10.7755/MFR.80.3.3 tion is in danger of extinction in the foreseeable future unless factors that are impeding recovery are identified and mitigated (Hobbs et al. ${ }^{1}$ ). Their critical habitat was designated in 2011 (NOAA, 2011) and is in close proximity to the greatest concentration of Alaska's human population and the largest urban area in the state, exposing belugas to a wide variety of stressors (Rugh et al., 2010).

Belugas are predominately found in near-shore waters of Cook Inlet, adjacent to many human activities, including fishing, hunting, timber harvest, mining, shipping, dredging, renewable energy development, wastewater discharge, military operations, oil and gas development, transportation, and residential and industrial development. The Cook Inlet Beluga Recovery Plan (NMFS, 2016) considers anthropogenic noise as a serious threat to their

gas (Delphinapterus leucas). AFSC Proc. Rep. 2006-16, 74 p. (avail. online at www.afsc.noaa. gov/Publications/ProcRpt/PR\%202006-16.pdf). recovery and highlights the need to better understand its sources and effects on the population. However, the diversity and occurrence of anthropogenic noise sources in Cook Inlet have not yet been described or characterized in the context of their effects on Cook Inlet beluga communication and behavior.

Underwater noise is currently being regulated for common noise sources occurring in the inlet such as seismic surveys and pile driving. Mitigation is mainly focused on close-range injury effects defined as the onset of permanent threshold shift (PTS) and temporary threshold shifts (TTS) in marine mammal hearing, following the recently updated NOAA technical guidance report (NMFS, 2018). Although behavioral harassment is also considered as part of the mitigation, a small number of takes is often allowed because of the difficulties in monitoring the extensive areas ensonified to level B harassment threshold
ABSTRACT-Anthropogenic noise has been identified as a major threat for the recovery of the endangered Cook Inlet beluga, Delphinapterus leucas, population, but little is known about its occurrence in critical habitat. We analyzed 8,756 $h$ of acoustic recordings from different locations and months in Cook Inlet, Alaska, to describe anthropogenic noise, evaluate the potential for acoustic impact to Cook Inlet belugas, and provide management recommendations. Nine total sources of noise were identified: commercial ship, dredging, helicopter, jet aircraft (commercial or military non-fighter), fighter jet, propeller aircraft, outboard motor, pile driving, sub-bottom profiler, as well as four repetitive unidentified noise sources. Several noise metrics were compared across noise sources, months, and locations. A total of 6,263 anthropogenic acoustic events were detected and classified, for a total dura- tion of $1,025 \mathrm{~h}$ representing $11.7 \%$ of the sound recordings analyzed. Anthropogenic noise was present in every day sampled. The natural background noise (i.e., ambient noise without anthropogenic contribution), in areas where currents and vegetative debris did cause minimal selfnoise, was below 120 dBrms re. $1 \mu \mathrm{Pa}$ for $94 \%$ to $100 \%$ of the time; much lower than previously reported and unsupportive of the current application of the elevated behavioral harassment threshold for nonimpulsive noise of $125 d B_{r m s}$. Based on spectral received levels and spatial and temporal prevalence, several anthropogenic noise sources in Cook Inlet have the potential to chronically mask beluga communication and hearing in most of the locations and periods sampled for this study. Current activities (e.g., shipping, dredging) exceed behavioral harassment levels on a daily basis in a significant portion of the critical habitat. Ship noise was identified as the top priority focus for noise mitigation management actions. A high concentration of noise sources was identified in the lower region of Knik Arm. This area is recommended for further research to evaluate the potential for beluga displacement and the basis to start considering cumulative impact effects in the permitting process. The amount of detected unidentified machinery noise or unclassifiable noises highlights the need for further research in coordination with industry, in particular in areas of oil and gas production (i.e., Trading Bay) or intense shipping related activities (i.e., facilities). Finally, unpermitted activities were also detected suggesting the need for further enforcement and outreach to increase the awareness towards this endangered population of belugas and the negative consequences of underwater noise in their protected habitat. 
(120 $\mathrm{dB}^{2}$ for non-impulsive and 160 $\mathrm{dB}$ for impulsive sources, NOAA, 1995). Five previous acoustic studies collected noise data and suggested that the background noise in upper Cook Inlet may often exceed $120 \mathrm{~dB}$ re $1 \mu \mathrm{Pa}$ (Heenehan, 2009; Blackwell and Greene ${ }^{3}$; $\mathrm{URS}^{4}$; Šrović and Kendall $\left.^{5}, \mathrm{HDR}^{6}\right)$. These results led the NMFS to define an exception for upper Cook Inlet of $125 \mathrm{~dB}_{\mathrm{rms}}$ for behavioral harassment (level B take) by non-impulsive noise instead of the standard $120 \mathrm{~dB}_{\mathrm{rms}}$ limit $\left(\mathrm{NMFS}^{7}\right)$.

Beginning in 2008 acoustic data were collected nearly continuously over five years at 10 locations in upper, middle, and lower Cook Inlet; these recordings represent the most complete currently available set of sound recordings collected in Cook Inlet. The primary objective of the Cook Inlet Beluga Acoustics (CIBA) research program was to acoustically describe the seasonal occurrence of beluga; killer whales, Orcinus orca; and porpoises, Phocoena spp. (Lammers et

${ }^{2} \mathrm{~dB}$ values are referenced to $1 \mu \mathrm{Pa}$ unless otherwise noted.

${ }^{3}$ Blackwell, S. B., and C. R. Greene. 2002. Acoustic measurements in Cook Inlet, Alaska, during August 2001. Rep. for Natl. Mar. Fish. Serv. Greenridge Rep. \#271-1, Aug. 2002, 42 p. (avail. online at https://alaskafisheries.noaa.gov/ sites/default/files/CI_Acoustics_Final.pdf).

${ }^{4}$ URS. 2007. Port of Anchorage Marine Terminal Development Project underwater noise survey test pile driving program, Anchorage, Alaska. Final underwater noise report. Prep. by URS for U.S. Dep. Transp. Marit. Admin. (avail. online at https://alaskafisheries.noaa.gov/sites/default/ files/2007underwaternoise.pdf).

${ }^{5}$ Širović, A., and L. S. Kendall. 2009. Passive acoustic monitoring of Cook Inlet beluga whales. Analysis report. Prep. by AK Pacific University for Port of Anchorage. Dec. 2009, 73 p. (avail. online at www.nmfs.noaa.gov/pr/pdfs/permits/ poa_acoustic_report.pdf).

${ }^{6} \mathrm{HDR} .2011$. Ambient noise measurements near the proposed Knik Arm Crossing Site during May and July 2010. Prep. by HDR Alaska Inc. for Knik Arm Bridge and Toll Authority, Anchorage, Feb. 2011, 63 p. (on file at Alaska Dep. Transport. Pub. Facil., Anchorage).

${ }^{7}$ NMFS. 2009. Endangered Species Act: Section 7 Consultation Biological Opinion for the Marine Terminal Redevelopment Project at the Port of Anchorage. U.S. Dep. Commer., NOAA, Natl. Mar. Fish. Serv., Alaska Reg. (avail. online at https://alaskafisheries.noaa.gov/sites/default/ files/poa_biop0709.pdf).

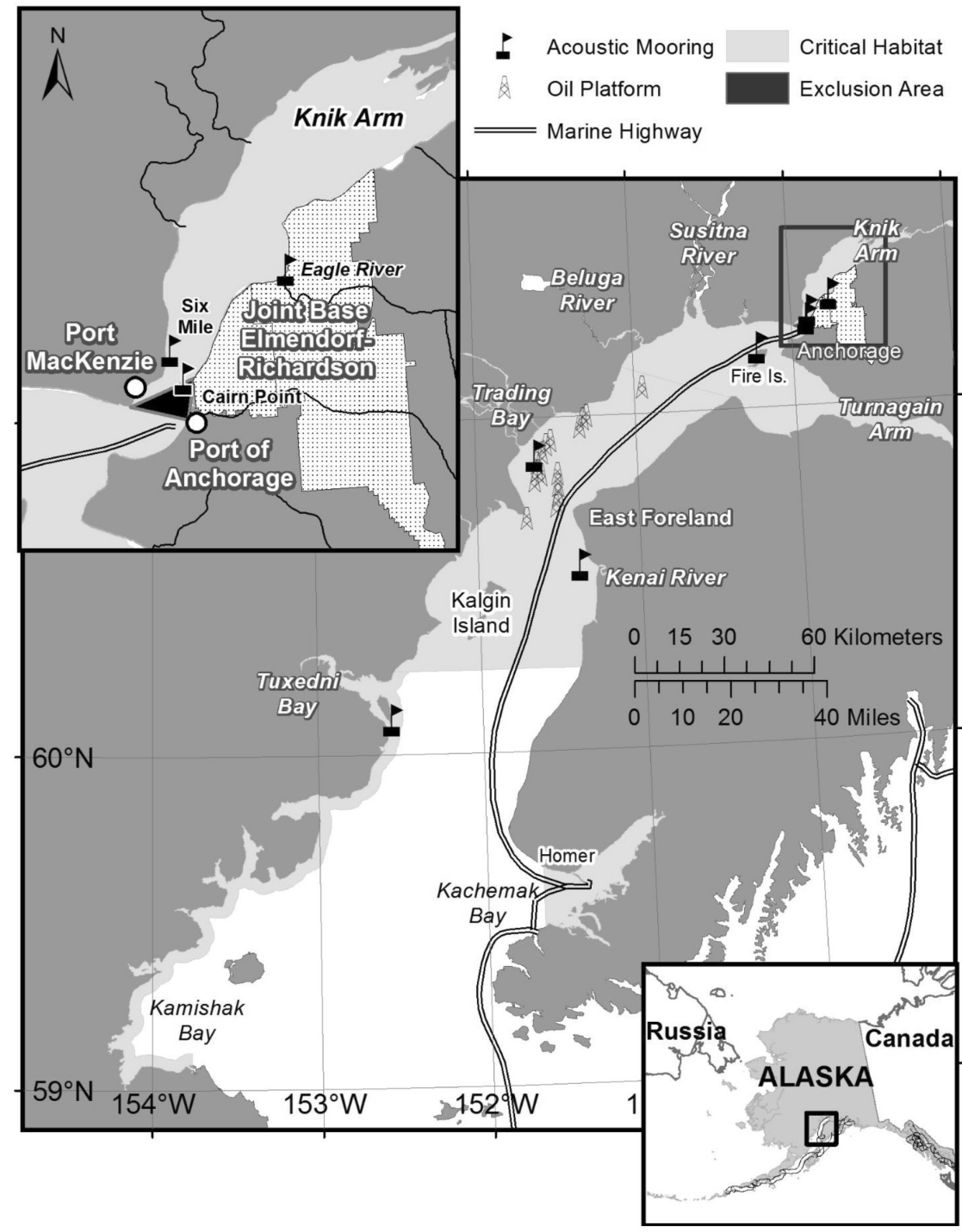

Figure 1.-Cook Inlet, Alaska, with the location of the CIBA acoustic moorings selected for this study, the Cook Inlet beluga critical habitat, main shipping routes, and oil and gas platforms.

al., 2013; Castellote et al. ${ }^{8}$; Castellote et al., 2016); documenting anthropogenic noise sources was a secondary objective. Here, we describe the background noise and anthropogenic con-

${ }^{8}$ Castellote, M., R. J. Small, J. Mondragon, J. Jenniges, and J. Skinner. 2016. Seasonal distribution and foraging behavior of Cook Inlet belugas based on acoustic monitoring. Alaska Dep. Fish Game, Final Wildl. Res. Rep., ADFG/ DWS/WRR-2016-3, Juneau (avail. online at http://www.adfg.alaska.gov/static/home/library/ pdfs/wildlife/research_pdfs/wrr_2016_3_seasonal_distribution_foraging_cook_inlet_belugas_acoustic_monitoring.pdf) tributors identified in a subset of these data (Fig. 1, Table 1), and, in line with proposed recovery actions (NMFS, 2016), we discuss a series of recommendations in the context of potential acoustic impact to Cook Inlet belugas and their recovery.

\section{Materials and Methods}

\section{Selection of Data Sets for Anthropogenic Noise Analysis}

Overall, the sound recording methods used by the CIBA research pro- 
Table 1. - List of acoustic mooring locations and time periods selected for the anthropogenic noise study in Cook Inlet, Alaska, July 2008-May 2013. For each location, the month, year, and number of days of recordings that were analyzed for noise events is listed.

\begin{tabular}{|c|c|c|c|}
\hline General area & Mooring location & $\begin{array}{l}\text { Month, year } \\
\text { (No. of days) }\end{array}$ & Total days \\
\hline Upper Knik Arm & Eagle River & $\begin{array}{l}\text { August } 2010 \text { (31) } \\
\text { September } 2010 \text { (28) }\end{array}$ & 59 \\
\hline Lower Knik Arm, west side & Six Mile & $\begin{array}{l}\text { December } 2011(29) \\
\text { May } 2012(21)\end{array}$ & 50 \\
\hline Lower Knik Arm, east side & Cairn Point & $\begin{array}{l}\text { August } 2010(31) \\
\text { April } 2011 \text { (3) }\end{array}$ & 34 \\
\hline Upper Inlet & Fire Island & $\begin{array}{l}\text { August } 2009(23) \\
\text { September } 2009 \text { (28) }\end{array}$ & 51 \\
\hline Upper Inlet & Trading Bay & $\begin{array}{l}\text { February } 2012(29) \\
\text { March } 2012(31) \\
\text { April } 2012(21)\end{array}$ & 81 \\
\hline Lower Inlet & Kenai River & April 2012 (21) & 21 \\
\hline Lower Inlet & Tuxedni Bay & March 2012 (31) & 31 \\
\hline
\end{tabular}

gram allowed accurate measurement of received noise levels because the recording system is calibrated (Lammers et al., 2013). However, the measurement of high amplitude anthropogenic noises was compromised because these recording methods aimed to maximize detection of faint beluga signals (see Methodological Limitation \#2 below). For this reason, we are only characterizing the noise events that exceeded the acoustic threshold for behavioral harassment (level B takes) for continuous sources $\left(120 \mathrm{~dB}_{\text {rms }}\right.$ for the lower inlet and $125 \mathrm{~dB}_{\text {rms }}$ for the upper inlet) and report when sources get near the $160 \mathrm{~dB}_{\mathrm{rms}}$ impulsive threshold.

Noise events that could exceed the threshold for injury (level A takes) cannot be properly reported with these data because they exceeded the dynamic range of the recording system. Furthermore, the moorings were designed to survive the harsh conditions of upper Cook Inlet, rather than avoid self-noise generated by strong currents and debris hitting the mooring and acoustic instruments; such noise compromised the description of anthropogenic noise events occurring during high current periods.

Details of the sampled locations and recording periods selected for this study are listed in Table 1. For this study, upper inlet refers to all areas north of the East and West Forelands in Figure 1. A subset of these data were not included in this study; similarly, areas where anthropogenic activities were abundant but belugas were absent were also not included. These selection criteria purposely focused noise analysis efforts on data from periods and locations with a strong overlap in beluga and anthropogenic noise occurrence.

\section{Acoustic Recordings}

Between 2008 and 2013 Ecological Acoustic Recorders (EARs, sensitivity of $-193.5 \mathrm{~dB}$, and flat response $\pm 1.5 \mathrm{~dB}$ from $10 \mathrm{~Hz}$ to $28 \mathrm{kHz}$ ) were deployed year-round throughout Cook Inlet. EARs were deployed on custom designed low-profile moorings to resist the harsh conditions of the inlet (Lammers et al., 2013; Castellote et al., 2016). Acoustic data were sampled at a rate of $25 \mathrm{kHz}$, which resulted in recordings obtained from 0.01 to 12.5 kHz. A $10 \%$ duty cycle was used to prolong battery life which resulted in a recording file of $30 \mathrm{sec}$ in duration every $5 \mathrm{~min}$ throughout the $24 \mathrm{~h}$ cycle.

\section{Detection and Classification of Anthropogenic Noise Events}

Raw data from binary EAR files were converted into ewav files for analysis; these files are similar to the standard sound wave (.wav) digital audio format. Analysis of ewav files was conducted using the MATLAB-based program Triton ${ }^{9}$ (Scripps Inst. Oceanogr., La Jolla, Calif.) to view longterm spectrograms of ewav files, play back recorded sounds, and detect and classify anthropogenic noise events. Acoustic data were averaged over 5 $\mathrm{sec}$ to generate long-term spectrograms, but when measurements of specific selections occurred, the data were processed from uncompressed, nonaveraged raw files. The following nine classes of anthropogenic noise events were identified (listed alphabetically):

1) Commercial ship,

2) Dredging,

3) Helicopter,

${ }^{9}$ Reference to trade names or commercial firms does not imply endorsement by the National Marine Fisheries Service, NOAA. 
4) Jet aircraft-commercial or military non-fighter ${ }^{10}$,

5) Jet aircraft - military fighter,

6) Outboard motor (small skiffs, rafts),

7) Pile driving (impact hammer method),

8) Propeller aircraft, and

9) Sub-bottom profiler.

As well as four repetitive unidentified noise sources:

10) Unclassified machinery (continuous mechanical sound; e.g., engine),

11) Unidentified "clank or bang" (impulsive mechanical sound; e.g., dumping hard material into a barge) $)^{11}$,

12) Unknown up- or down-sweep (modulated tone of mechanical origin; e.g., friction originated by hydraulic systems), and

13) Unidentified (unclassifiable anthropogenic sound).

Classification of anthropogenic events was made manually by playing and inspecting the spectrogram of each signal. A classification scheme was developed using spectrogram images with sections of ewav files used as reference for comparison. Only unequivocally identified events were assigned to known noise source classes, and events whose source was uncertain were classed as "unidentified" or "unclassified" to minimize error. Only noises that were clearly from anthropogenic origin were included in the analysis.

If an event was detected in two or more consecutive files, it was presumed that this signal was sustained throughout the entire $5 \mathrm{~min}$ standby cycle. Multiple noise events that overlapped and events masked by selfnoise from high current flow were only examined to account for their duration, but they were not used for other acoustic measurements since discerning acoustic energy from the overlapped

\footnotetext{
${ }^{10}$ In the figures, this noise class is labeled "Jet aircraft-military non-fighter" to reduce the length of the legends.

${ }^{11}$ Clank or bangs were discrete events but often occurred in series with random intervals.
}

events or from the event and the current flow noise was not possible. However, in many occasions, impulsive noises occurred only during continuous noise events. These were assumed to originate from the same source and thus were selected for the analysis (e.g., a towed barge could generate both the noise of the tug boat engine and clanking noises from the chains used to tow the barge).

The Port of Anchorage (POA) provided the "ship recall logs" for the periods of data analyzed. These logs present information on the temporal presence of commercial ships. Data from these logs were compared with recordings from the Cairn Point, Six Mile, and Fire Island moorings in an attempt to reclassify unclassified machinery events as commercial ship noise.

Arrival and departure times of commercial vessels were extracted from the POA logs and $30 \mathrm{~min}$ prior to arrival times in the $\log$ and $30 \mathrm{~min}$ after departure time in the log were considered to include tugboat operations associated with commercial vessels (Ribuffo ${ }^{12}$ ). Initially, a "tug boat" noise classification was used, but distinguishing between noise from tugs and commercial vessels was too challenging, often with complete overlap in occurrence. Thus, this noise class was not included in the analysis and both tug and commercial ship noise were grouped under ship noise class.

\section{Noise Measurements}

The system gain and frequency responses were factored in all noise measurements for each instrument, such that absolute $\mathrm{dB}$ values were obtained; i.e., re $1 \mu \mathrm{Pa}$ (unless a different reference is specified).

Five acoustic metrics were calculated using custom written Matlab codes:

1) Root Mean Square (RMS) sound pressure level (SPL) $\left(\mathrm{dB}_{\mathrm{rms}}\right)$ : Calculated over the total duration of each event (defined in metric 3) and the full band of the recording

\footnotetext{
${ }^{12}$ Ribuffo, S. Port Director, Anchorage. Personal
} commun., 2 Aug. 2013.
$(0.01-12.5 \mathrm{kHz})$. There were negligible differences in $\mathrm{dB}_{\mathrm{rms}}$ when measured over the full band (0.01$12.5 \mathrm{kHz}$ ) or just over frequencies affected by each noise event, because most events influenced the full recorded range of $0.01-12.5$ $\mathrm{kHz}$.

2) Power spectral density in $1 / 3$ octave band levels (in $\mathrm{dB}$ re $\mu \mathrm{Pa}^{2}$ / $\mathrm{Hz}$ ): Corresponds to mean values of 30 frequency bands for each noise class; results from this metric were processed to present a histogram with counts of $1 / 3$ octaves with maximum amplitude (peak bands) per noise class. This histogram provides an overview of the dominant $1 / 3$ octave bands for each noise class. Spectrum levels (in $\mathrm{dB}$ re $1 \mu \mathrm{Pa}^{2} / \mathrm{Hz}$ ) for these dominant bands were calculated in Castellote et al. ${ }^{13}$ and are stated in the results together with $1 / 3$ octave band results.

3) Duration of event: measured as the difference between the end and start times, including recording standby periods when events spanned over multiple consecutive files. This metric is also provided as the mean duration and standard deviation for each noise class, including all the events detected in each location and month. For events occurring in sequences (i.e., pile driving, sub-bottom profiler, and clank or bang), the duration comprised the time elapsed from the onset of the first detected signal to the last one in the sequence. But see Methodological Limitation 2 related to this metric in the next section.

4) Sound exposure level (SEL, in $\mathrm{dB}$ re $\left.1 \mu \mathrm{Pa}^{2}-\mathrm{s}\right)$ : Defined as $\mathrm{rms}(\mathrm{SPL})$ $+\log (\mathrm{T})$ where $\mathrm{T}$ is the duration of the event, including standby periods when the detection spans

${ }^{13}$ Castellote M., B. Thayre, M. Mahoney, J. Mondragon, C. Schmale, and R. J. Small. 2016. Anthropogenic noise in Cook Inlet beluga habitat: sources, acoustic characteristics, and frequency of occurrence. Final Wildl. Res. Rep. ADFG/ DWC/WRR-2016-4. Alaska Dep. Fish Game, Juneau. (avail. online at http://www.adfg.alaska. gov/static/home/library/pdfs/wildlife/research_ pdfs/wrr_2016_4_anthropogenic_noise_cook_inlet_beluga_habitat.pdf). 
consecutive sound files or the interval between consecutive signals if they are generated in a sequence. Although we acknowledge that we have no control over changes in received levels (RL) during the standby periods. Note this metric is commonly described as cumulative SEL $\left(\mathrm{L}_{\mathrm{E}}\right)$ by NMFS (2016).

5) Pressure in $d_{B}$ zero-peak: Calculated by finding the maximum pressure in $\mathrm{dB}_{0 \text {-peak }}$ with a time resolution of $0.05 \mathrm{~s}$. This metric is suitable for impulsive signals and is a good replacement for sound pressure level (SPL) in $\mathrm{dB}_{\text {rms }}$ because signals of short duration are problematic for $\mathrm{dB}_{\mathrm{rms}}$ calculation (Madsen, 2005).

\section{Natural Ambient Noise Measurements}

A substantial portion of our data was not considered to be a good representation of the natural ambient noise conditions in Cook Inlet (i.e., background noise without self-noise or anthropogenic contribution) due to the amount of anthropogenic noise events in all the locations sampled. Therefore, to minimize the effects of anthropogenic noise, measurements were done only with recording periods excluding any anthropogenic noise event. Using custom written Matlab code, these recording periods were binned in $5 \mathrm{~min}$ intervals to calculate SPL over the full band of the recording (0.01-12.5 $\mathrm{kHz}$ ), and power spectral density percentiles for each mooring location and month. Percent of time below $120 \mathrm{~dB}_{\mathrm{rms}}$, within $120-125 \mathrm{~dB}_{\mathrm{rms}}$, and above $125 \mathrm{~dB}_{\mathrm{rms}}$ was also calculated. It should be noted that for most sampled locations in the upper inlet, high water current levels generated flow noise at the hydrophone, and vegetative debris colliding with the moorings caused impulsive noise. These artificially elevated noise periods occurred periodically, were not removed for the analysis, and are reflected in the higher end $\mathrm{dB}$ values reported here.

\section{Comparisons to Beluga Hearing}

Noise class and natural ambient noise spectral density results were compared against current knowledge on beluga whale hearing thresholds (Awbrey et al., 1988; Castellote et al., 2014) to highlight the potential for hearing and communication masking. Two factors play an important role in this comparison. The first factor is that only a few studies describe beluga critical ratios and auditory filters, with a limited number of animals sampled and varied methods, providing high variability in results (Johnson et al., 1989; Klishin et al., 2000; Finneran et al., 2002; Erbe et al., 2008). The second factor is the unknown capacity of belugas to cope with masking noise, and the potential for masking release mechanisms, is a topic barely studied in beluga whales (Erbe et al., 2016). Thus, as a first step in this comparative approach, we have used a frequency summation of $1 / 3$ octave bands, a common and conservative bandwidth over which to compare spectral density results to hearing thresholds. We have not attempted to factor critical ratios or masking release mechanisms into the comparison between hearing thresholds and spectral density of detected noise, thus our results should be considered conservative. More details on beluga masking release, auditory filters, and critical ratios would be required to improve this comparative approach.

\section{Methodological Limitations}

Because the study was designed primarily to collect data relevant to the long-term detection of beluga whale signals (Lammers et al., 2013; Castellote et al., 2016) and not anthropogenic noise, three important limitations must be acknowledged:

1) Recorder power consumption was a limiting factor for long-term recordings. The sampling rate and the duty cycle were adjusted to reduce power consumption in each recorder. Since the primary objective of this study was to detect beluga vocalizations, a sampling rate was selected high enough to collect the frequencies where most of the acoustic energy of beluga social calls is centered, $(0.01-12.5 \mathrm{kHz}$; Lammers et al., 2013). Any anthropogenic noise generating acoustic energy only above $12.5 \mathrm{kHz}$ would not be detected in our recordings. Although this is a limitation, most of the anthropogenic noises had acoustic energy below $12.5 \mathrm{kHz}$. Only depth/fish sounders, scientific echo sounders, and military sonar are able to generate acoustic energy exclusively above $12.5 \mathrm{kHz}$. Of these, only depth/fish sounders are commonly used in Cook Inlet, although these noise sources are always associated with shipping noise, which is detected within the $0.01-12.5 \mathrm{kHz}$.

2) The duty cycle $(10 \%)$ used to obtain months-long deployment durations resulted in sound files of 30 $\mathrm{sec}$ in duration. Noise events longer than $30 \mathrm{sec}$ or truncated at the beginning or end of the $30 \mathrm{sec}$ files, resulted in all pressure-related measurements (i.e., SPL, SEL, peak pressure) being inherently conservative; duration measurements, however, were only partially truncated because the standby interval was accounted for when signals lasted more than one consecutive file. The total number of events or the total time for each noise class and its reported percentage is underrepresented because any event that fell into the standby period could not be detected. Therefore, absolute presence of anthropogenic noise cannot be directly measured with these data.

3) For all CIBA deployments, the recording gain was set on the EARs to enhance the detection of faint, far away beluga vocalizations. This gain setting shifted the dynamic range of the recorder to lower received levels and compromised the recording quality of high amplitude signals, as they become saturated by too much gain and are no longer useful to reliably provide any sound pressure-based characteristic. Signals with sound amplitude higher than $153 \mathrm{~dB}$ (peak to peak) were at the limit of the EAR system to accu- 
rately record the signal. For a perfect sinusoid wave the SPL in $\mathrm{dB}_{\text {rms }}$ will be $9 \mathrm{~dB}$ below the peak value, putting the SPL $\mathrm{dB}_{\text {rms }}$ upper limit at $144 \mathrm{~dB}$. When $153 \mathrm{~dB}$ peak or $144 \mathrm{~dB}_{\mathrm{rms}}$ is exceeded, the recorded waveform becomes clipped (i.e., the upper and lower limits of the waveform are cut). While clipped signals are still recorded and can be identified, measurements of their magnitude or contribution at different frequencies becomes biased. This limitation impedes an accurate assessment of signals with the highest $\mathrm{dB}$ levels. For the survey of the density and distribution of noise events, clipped events were included with non-clipped events in the results. Because of this limitation, overall sound pressure and sound exposure levels should be considered lower than what was present in the study area. See the CIBA final report on anthropogenic noise (Castellote et al. ${ }^{13}$ ) for an occurrence analysis of clipped events.

Additionally, one more methodological limitation inherent to mooring sound recorders in the upper section of Cook Inlet is the high current periods associated to the extreme tidal cycles that typically occur in this region. Large tides, exceeding $10 \mathrm{~m}$, produce strong currents and tidal bores with speeds of up to $5 \mathrm{~m} / \mathrm{sec}$ (Ezer et al., 2008). The flow noise generated by high water flow around a static hydrophone capsule is dependent on the intensity of turbulence and the transducer geometry and is observed to frequencies greater than $500 \mathrm{~Hz}$. (Bassett et al., 2014). Some recorders have been fitted with a flow shield made of open cell foam or mesh around the hydrophone capsule to reduce flow noise (e.g., Greene et al., 2004); however, in Cook Inlet, because of the high density of suspended glacial silt throughout the water column $(>1700 \mathrm{mg} / \mathrm{l}$ near Anchorage; Wright et al., 1973), flow shields would quickly get clogged with silt increasing sound attenuation and altering the system's frequency response. Only deployment locations in the upper inlet were affected by flow noise (Eagle River, Six Mile, Cairn Point, and Fire Island) during current peak periods.

\section{Results and Discussion}

\section{Spatial and Temporal Occurrence of Anthropogenic Noise}

A total of 6,263 anthropogenic acoustic events were present in the $8,756 \mathrm{~h}$ of data selected for our analysis. These events had a summed duration of $1,025 \mathrm{~h}$ which represented $11.7 \%$ of the sound recordings analyzed. In total, we identified 13 anthropogenic noise classes. The presence of anthropogenic noise in only $11.7 \%$ of the selected data could be inferred as a minor disturbance; however, anthropogenic noise was neither homogenously distributed across the inlet nor across seasons, and areas and periods of high noise concentration were common.

In general, during winter months the lower inlet was much quieter than the upper inlet. When measuring the temporal persistence of each noise class by location and month, commercial shipping noise dominated the soundscapes in both the upper and lower inlet, except in Eagle River, as this location is not navigable for commercial vessels and was the least disturbed of all sampled locations.

Commercial ship noise events were slightly longer in duration in the lower inlet compared to the upper inlet, which could be related to differences in speed. Ships moving slower in the upper inlet will cause lower source levels and shorter detection ranges. But longer durations in ship noise could also be related to improved sound propagation by deeper and less restricted waters in the lower inlet.

Figure 2 shows a clear comparison of overall mean SPL for detected anthropogenic noise in each sampled location and month. The highest amplitude and longest anthropogenic activities occurred at Cairn Point, the mooring location closest to the POA, particularly in summer. When considering the amount of recording time and the total duration of anthropo- genic noise event in each location, the highest percentage of time with anthropogenic noise (50.3\%) and the highest number of noise sources also occurred at Cairn Point (Table 2 ). The seasonal increase in number of events at Cairn Point is due to increased port activity when ice is absent (generally May to October). Other summer-related activities in this area also increased (e.g., operative public launch ramp, port dredging operations, etc.). These changes are clearly evident by the substantial difference in the number of detected events per day for each class at Cairn Point in April (19.3) vs. August (153.5) in Table 2.

The lower section of Knik Arm is a particularly important beluga corridor in summer. Belugas must pass by the Cairn Point area when moving into and out of Knik Arm, which is considered an important foraging area within their critical habitat (NMFS, 2008) and potentially a nursery area (Huntington, 2000; Hobbs et al., 2015). Saxon Kendall et al. (2013) suggested that belugas might be displaced towards the west side of lower Knik Arm when transiting the Cairn Point area due to the noise generated along the eastern shore near the POA. The duration and diversity of anthropogenic noise classes are relatively similar between Cairn Point and Six Mile (Table 2, Fig. 3), yet the amount of detected events per day at Cairn Point was much higher than at Six Mile (Table 2).

Our results indicate that although physical displacement of belugas from the waters around the POA could reduce their exposure to anthropogenic noise as the whales transit through the lower Knik Arm, the exposure is still considerable at the western side of lower Knik Arm. Specifically, Port MacKenzie is located on the west side of the arm, and even if this is a smaller port than POA, a bulk head barge dock and a deep-draft dock are commonly used there.

Activities at Port MacKenzie are likely important contributors to anthropogenic noise on the western side 
Table 2.-Anthropogenic noise classes and number of events, grouped by location and month, detected in the seven locations sampled in Cook Inlet, Alaska, during the period August 2009-May 2012. Note that different noise classes were detected in each location, and some months were not entirely sampled.

\begin{tabular}{|c|c|c|c|c|c|}
\hline Location Month & Noise class & No. of events & Location Month & Noise class & No. of events \\
\hline Eagle River & & & Fire Island & & \\
\hline August 2010 & Aircraft-non-fighter & 1 & August 2009 & Jet aircraft-non-fighter & 11 \\
\hline \multirow[t]{6}{*}{ (31 days) } & Jet aircraft-military fighter & 30 & (23 days) & Commercial ship & 155 \\
\hline & Outboard motor jet & 21 & & Jet aircraft-military fighter & 3 \\
\hline & Propeller aircraft & 2 & & Outboard motor & 10 \\
\hline & Unidentified & 1 & & Pile driver & $24^{1}$ \\
\hline & Monthly total & $\overline{55}$ & & Sub-bottom profiler & $1^{1}$ \\
\hline & No. of events/day & 1.8 & & Unclassed machinery & 26 \\
\hline \multirow{5}{*}{$\begin{array}{l}\text { September } 2010 \\
\text { ( } 28 \text { days) }\end{array}$} & Jet aircraft-military fighter & 38 & & Unidentified & 32 \\
\hline & Outboard motor & 7 & & Unidentified clank bang & $\frac{14}{1070}$ \\
\hline & Unidentified & 4 & & $\begin{array}{l}\text { Monthly total } \\
\text { No. of events/day }\end{array}$ & $\begin{array}{r}276 \\
12\end{array}$ \\
\hline & Monthly total & $\overline{49}$ & & No. of events/day & \\
\hline & No. of events/day & 1.8 & September 2009 & Jet aircraft-non-fighter & 35 \\
\hline \multirow{10}{*}{$\begin{array}{l}\text { Six Mile } \\
\text { May } 2012 \\
\text { (21 days) }\end{array}$} & & & (28 days) & Commercial ship & 123 \\
\hline & Jet aircraft-non-fighter & 4 & & Jet Aircraft-military fighter & 1 \\
\hline & Commercial ship & 42 & & Propeller aircraft & 2 \\
\hline & Dredging & 27 & & Unclassed machinery & 3 \\
\hline & Jet aircraft-military fighter & 4 & & Unidentified & 17 \\
\hline & Pile driving & $22^{1}$ & & Monthly total & $\overline{181}$ \\
\hline & Unclassed machinery & 5 & & No. of events/day & 6.5 \\
\hline & Unidentified clank bang & 11 & Trading Bay & & \\
\hline & Monthly total & $\frac{11}{115}$ & February 2012 & Commercial ship & 94 \\
\hline & No. of events/day & 5.5 & (29 days) & Unclassed machinery & 23 \\
\hline \multirow{8}{*}{$\begin{array}{l}\text { December } 2011 \\
\text { (29 days) }\end{array}$} & Jet aircraft-non-fighter & 22 & & Monthly total & 117 \\
\hline & Commercial ship & 22 & & No. or events/day & 4 \\
\hline & Helicopter & 7 & March 2012 & Commercial ship & 88 \\
\hline & Jet aircraft-military fighter & 1 & (31 days) & Unclassed machinery & $\begin{array}{r}115 \\
1\end{array}$ \\
\hline & Unclassed machinery & 73 & & Monthly total & $\frac{1}{204}$ \\
\hline & Unidentified & 2 & & No. of events/day & 6.6 \\
\hline & Monthly total & $\frac{4}{131}$ & April 2012 & Commercial ship & 62 \\
\hline & No. of events/day & 4.5 & (21 days) & Unclassed machinery & 144 \\
\hline \multirow{10}{*}{$\begin{array}{l}\text { Cairn Point } \\
\text { April } 2011 \\
\text { (3 days) }\end{array}$} & & & & Unidentified & 2 \\
\hline & Commercial ship & 5 & & Monthly total & $\overline{208}$ \\
\hline & Dredging & 42 & \multirow{12}{*}{$\begin{array}{l}\text { Kenai } \\
\quad \begin{array}{l}\text { April } 2012 \\
\text { (21 days) }\end{array}\end{array}$} & No. of events/day & 10 \\
\hline & Outboard motor & 4 & & & \\
\hline & Propeller aircraft & 3 & & Commercial ship & 70 \\
\hline & Unclassed machinery & 1 & & Jet aircraft-non-fighter & 2 \\
\hline & Unidentified & 1 & & Outboard motor & 6 \\
\hline & Unidentified clank bang & 2 & & Pile driving & $1^{1}$ \\
\hline & Monthly total & $\frac{2}{58}$ & & Propeller aircraft & 1 \\
\hline & No. of events/day & 19.3 & & Sub-bottom profiler & $1^{1}$ \\
\hline August 2010 & Jet aircraft-non-fighter & 7 & & Unclassed machinery & 3 \\
\hline (31 days) & Commercial ship & 1,832 & & Unidentified & $\frac{1}{25}$ \\
\hline & Dredging & 36 & & $\begin{array}{l}\text { Monthly total } \\
\text { No of events/day }\end{array}$ & 85 \\
\hline & Jet aircraft-military fighter & 13 & & No. OI events/day & \\
\hline & Unclassed machinery & 412 & \multirow{7}{*}{$\begin{array}{l}\text { Tuxedni } \\
\text { March } 2012 \\
\text { (31 days) }\end{array}$} & Commercial ship & 22 \\
\hline & Unidentified & 109 & & Propeller aircraft & 1 \\
\hline & Unidentified clank bang & 1,884 & & Unclassed machinery & 1 \\
\hline & Unknown up or down sweep & 464 & & Unidentified & 3 \\
\hline & Monthly total & $\overline{4,757}$ & & Unidentified clank bang & 1 \\
\hline & No. of events/day & 153.5 & & Monthly total & $\overline{28}$ \\
\hline & & & & No. of events/day & 1 \\
\hline
\end{tabular}

${ }^{1}$ These values reflect the number of sequences detected but not the number of events within each sequence.

of lower Knik Arm. Importantly, anthropogenic noise in this area is concentrated in the summer months (Table 2 ), when belugas use this area more intensely, accessing the upper areas of Knik Arm to feed on anadromous fish runs such as eulachon, Thaleichthys pacificus, and salmon (Goetz et al., 2012).

Persistent shipping noise was recorded at Trading Bay but at lower received levels than Cairn Point or Fire Island (Fig. 4A). The main shipping route to or from Anchorage is further away from the Trading Bay mooring than the Fire Island and Cairn Point moorings, so the shipping noise in
Trading Bay may be from activities associated with the numerous offshore oil and gas platforms (Fig. 1). Unclassified machinery noise was very persistent in Trading Bay and was likely related to the high concentration of oil and gas production operations in this area (subsea production machinery, pipelines connecting offshore platforms to land facilities, etc.). The acoustic footprint of this industry has barely been described in Cook Inlet, and thus many of the recursive machinery noises detected here remain unclassified.

Eagle River and Tuxedni Bay were the two locations with the lowest over- all occurrence of anthropogenic noise and lowest overall mean SPL for anthropogenic events (98.8 and 98.9 $\mathrm{dB}_{\mathrm{rms}}$, respectively, Fig. 2). Both areas are relatively isolated from anthropogenic activities. Eagle River is mainly exposed to jet aircraft noise (Table 2) due to its proximity to the JBER. Noise from the Army's live fire training and detonations of high explosives on land were not detected. Outboard motor noise was also common in Eagle River, likely from small research vessels (e.g., JBER beluga studies, LGL photo-id studies) and occasional small fishing vessels transiting through the area. The upper Knik Arm sustains 


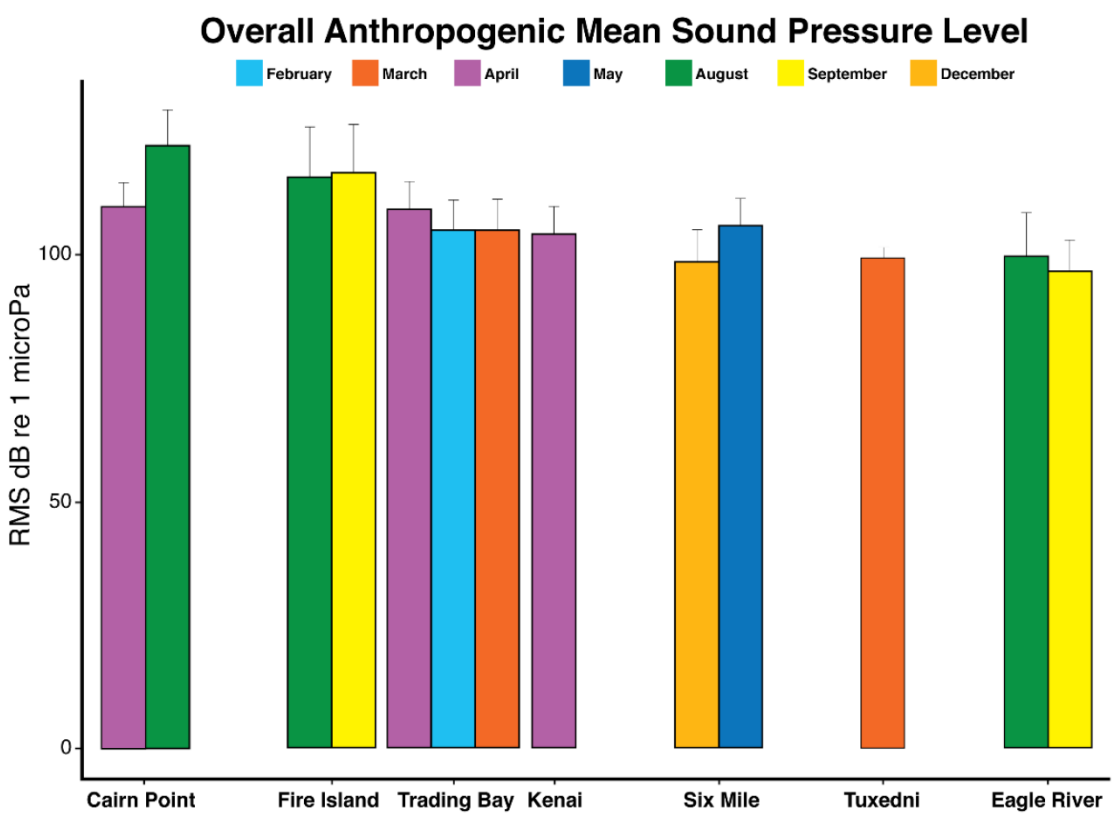

Figure 2.-Overall mean anthropogenic sound pressure level (SPL) calculated as $\mathrm{dB}_{\mathrm{rms}}$ re $1 \mu \mathrm{Pa}$ and standard deviation from all the anthropogenic noise events of each location and month, independently of the noise class. Locations are ordered from noisiest to quietest. Only months where data was sampled are included in the figure.

an important sport fishery but most of these small vessels access the Matanuska River and Knik River from boat launches in the lower portion of the rivers themselves (ADFG, 2015).

\section{Anthropogenic Noise Contributors in Cook Inlet}

\section{Commercial Shipping}

Commercial ships were the most prominent source of anthropogenic noise across Cook Inlet both in percent of overall anthropogenic noise time (63\% on average) and mean duration of the events (Fig. 3) and, for Fire Island, received SPL (mean of $119.9 \mathrm{~dB}_{\mathrm{rms}}$, Fig. 4A). For most locations, commercial shipping contribution to the background noise was well above the levels reported for heavy traffic by Richardson et al. (1995). Mean received SPLs at Cairn Point were very close to the levels at Fire Island (a difference of just $1.4 \mathrm{~dB}$ ), probably due to the proximity of the shipping route to the mooring locations (Fig. 1), but might also be related to the range over which tug munication in all sampled locations. estimated that when ship noise was highest, beluga communication and echolocation range was reduced by up to $85 \%$ of its expected value compared to natural noise conditions. Over 79\% of our reported SPL values for commercial ship noise were above 114.1 $\mathrm{dB}_{\mathrm{rms}}$ (Fig. 4A), therefore the potential communication and echolocation range reduction for Cook Inlet belugas may be even more extreme than in the Saguenay Fjord. Due to the clipping of commercial ship noise events at high levels, our data preclude an accurate description of the highest received levels. However, the results presented here are sufficient to highlight the potential for the acute masking of beluga communication over a wide temporal and spatial scale within their critical habitat.

Shipping traffic in Cook Inlet is reduced in winter by $15-20 \%$ and shipping speeds are lower when thick ice is present, but also the shipping route might be altered towards the east in the mid-inlet to avoid denser ice areas $\left(\right.$ Garay $\left.{ }^{14}\right)$. These changes could explain a reduction in noise levels for winter months, particularly for the western side of the mid-inlet (e.g., Trading Bay).

Six Mile is near Port MacKenzie but ship noise occurrence is lower and their SPLs (mean of $104.5 \mathrm{~dB}_{\mathrm{rms}}$ ) are not as high as in Cairn Point (mean of $118.5 \mathrm{~dB}_{\mathrm{rms}}$ ). However, highest received levels for ship noise events still exceeded $120 \mathrm{~dB}_{\mathrm{rms}}$ at Six Mile. Even if belugas could potentially be displaced towards the western side of the arm (Saxon Kendall et al., 2013), they would still be exposed to substantial ship noise levels. Figure 6 shows how ship noise SEL at both Cairn Point and Six Mile falls within approximately 125 to $150 \mathrm{~dB}$ with medians at 139 $\mathrm{dB}$ and $134 \mathrm{~dB}$, respectively. This suggests that when beluga are exposed to ship noise at the lower part of Knik Arm, the exposure might not be very different on either side of the arm.

Ship noise levels in Saguenay Fjord, St. Lawrence Estuary, Can., were reported in the range $102.1-114.1 \mathrm{~dB}_{\mathrm{rms}}$ (Gervaise et al., 2012). These authors
${ }^{14}$ Garay, P. Southwest Alaska Pilots Association, Homer, Alaska. Personal commun., 6 Oct. 2015. 


\section{Mean Event Duration and SD in Upper Cook Inlet}

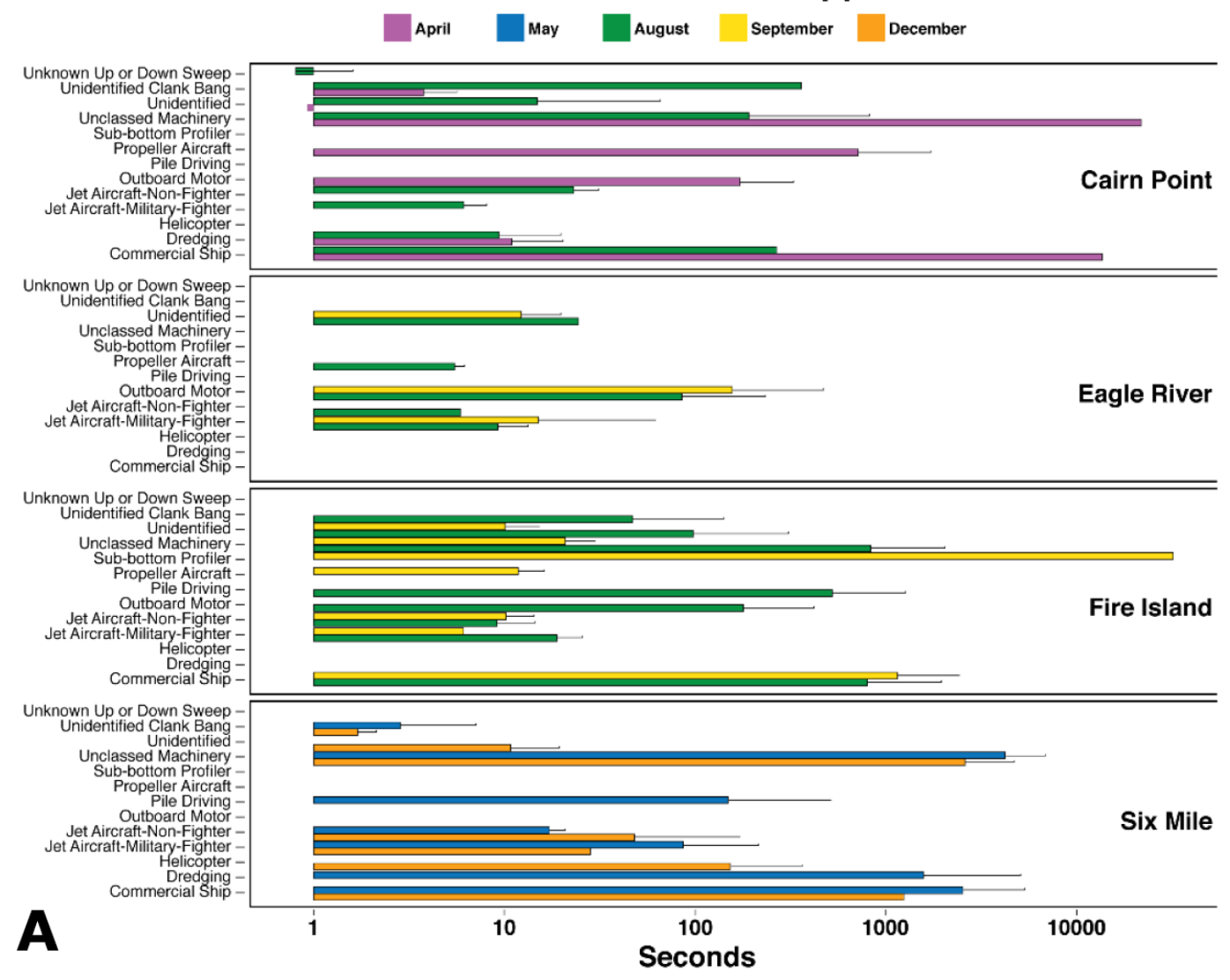

Figure 3.- Mean duration and standard deviation of noise classes detected at each site by month. Upper panel (A) includes the 4 locations sampled in the Upper Inlet (Cairn Point, Eagle River, Fire Island and Six Mile), and the lower panel (B) includes the 3 locations sampled in the Lower Inlet (Kenai, Trading Bay and Tuxedni). Note that a maximum of 3 mo per location were selected (see Table 1), therefore, not all months were sampled in all locations.

\section{Jet Aircraft Noise}

Because of the presence of the JBER in the vicinity of Knik Arm as well as the Anchorage International Airport, aircraft noise from commercial (e.g., 727, 747), fighter (e.g., F-15, F-22), and non-fighter military jets (e.g., C-17, E-3a) is a prevalent source of underwater noise in upper Cook Inlet, but is absent in the lower inlet. Distinguishing between commercial and military non-fighter jet aircraft was difficult as their underwater acoustic signatures were very similar. Therefore, these events were grouped in a single noise class termed jet aircraft. However, it is likely that events of this noise class in mooring locations closer to JBER are military non-fighter jet aircraft and events in mooring locations closer to the Anchorage International Airport are commercial jet aircraft.

Jet aircraft (non-fighter) was of highest amplitude in Cairn Point (mean of $125.7 \mathrm{~dB}_{\mathrm{rms}}$, maximum of $135.9 \mathrm{~dB}_{\mathrm{rms}}$, Fig. 4B), likely due to the proximity to the JBER. Fire Island is the second highest amplitude location for this noise class (mean of $106.2 \mathrm{~dB}_{\text {rms }}$, maximum of $126.44 \mathrm{~dB}_{\text {rms }}$, Fig. 4B) because the path for landing and take-off from the Anchorage International Airport east-west runways cross over this mooring location. The mooring location at Fire Island is further away from the airport than the mooring location at
Cairn Point is from the JBER, thus aircrafts tend to be higher in altitude than at Cairn Point, and the received SPLs tend to be lower.

Jet fighter noise occurrence was highest at Eagle River, but received levels (mean of $95.3 \mathrm{~dB}_{\text {rms }}$, maximum of $104.8 \mathrm{~dB}_{\text {rms }}$, Fig. $4 \mathrm{C}$ ) were consistently lower than at Cairn Point (mean of $124.8 \mathrm{~dB}_{\mathrm{rms}}$, maximum of $135.4 \mathrm{~dB}_{\text {rms }}$, Fig. 4C). The mooring location at Cairn Point was within the path for landing and take-off from the east-west runway at the JBER, and the mooring at Eagle River was in the path of the north-south runway but at a much larger distance. These results suggest that, for the months sampled, the north-south runway was more 


\section{Mean Event Duration and SD in Lower Cook Inlet}

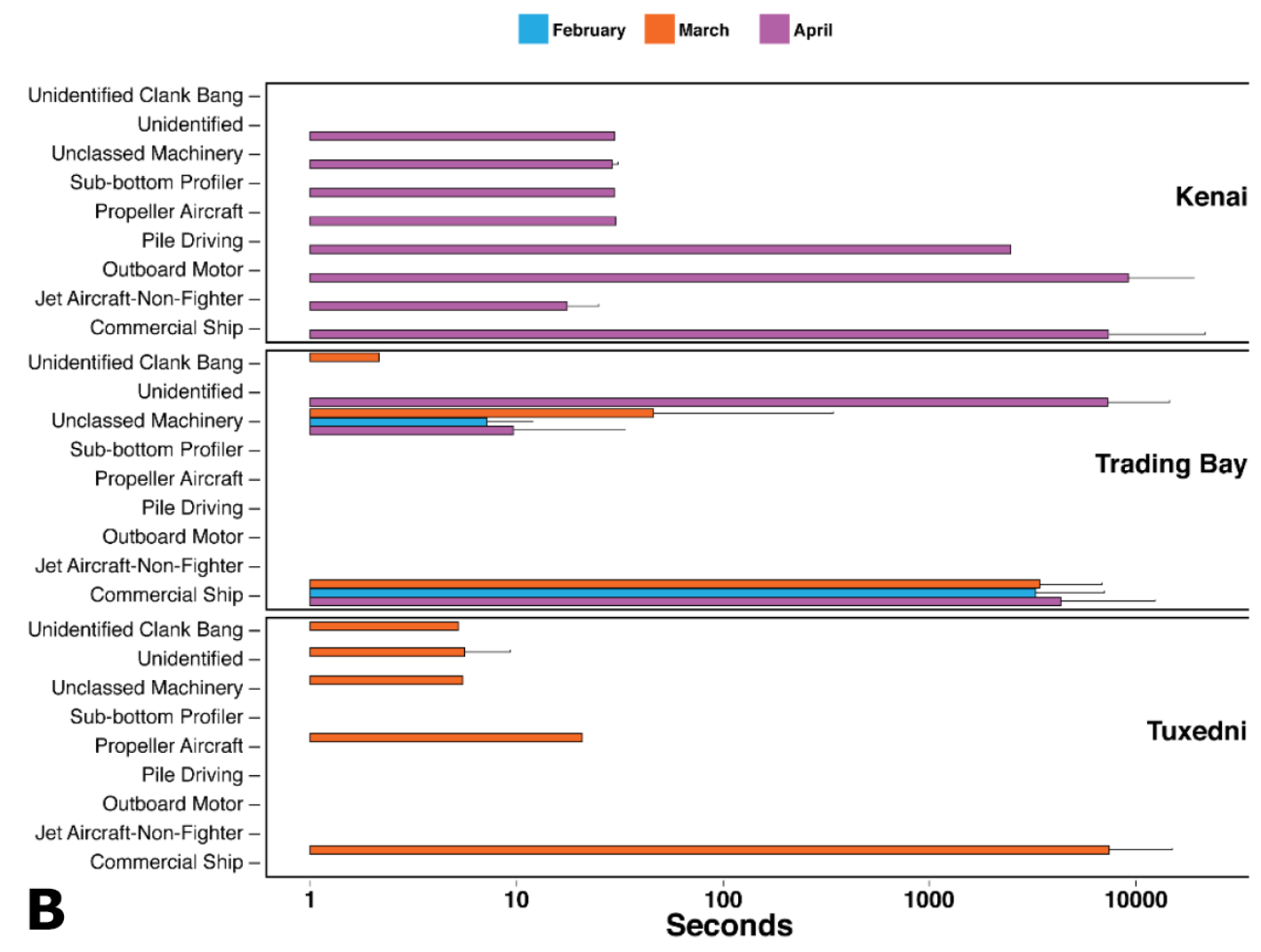

Figure 3.-Continued.

commonly used by jet fighters, and their overpass altitude was higher at Eagle River than Cairn Point.

Third octave band peak energy commonly occurred at the $315 \mathrm{~Hz}$ band for jet fighter noise and at more variable bands for other jet aircraft (Fig. $5 \mathrm{~B}$ and 5C). Beluga hearing threshold was exceeded by all bands above 500 $\mathrm{Hz}$ for both types of jet noise (Awbrey et al., 1988; Castellote et al., 2014). Thus, beluga can hear both jet aircraft and jet fighter noise when these happen, and this has the potential to generate masking of their hearing and communication signals. But, both jet aircraft and jet fighter noise events were always of very short duration (overall average of $14.2 \mathrm{sec}$ for jet aircraft and $10.4 \mathrm{sec}$ for jet fighter noise).

Jet fighter noise occurrence ranged from 0 to 4 events per day at Cairn Point (April and August), from 0 to
6 events per day at Fire Island (August and September), and from 0 to 9 events at Eagle River (August and September), which is representative for a $10 \%$ duty cycle recording scheme. Therefore, its equivalence would be 0 to 40 events per day at Cairn Point, 0 to 60 at Fire Island and 0 to 90 at Eagle River for the sampled months, although this assumes homogenous distribution of jet overpasses throughout the day, which is not realistic. Because the behavioral response of Cook Inlet belugas to jet aircraft and jet fighter noise in unknown, it is not clear if this noise disturbance should be a concern. Even if peak frequency bands are within the beluga hearing range, and received levels exceed the behavioral harassment threshold of $125 \mathrm{~dB}_{\mathrm{rms}}$ for some events, this sporadic and brief disturbance is unlikely to negatively impact belugas, unless these reach higher levels than the ones reported in this study.

\section{Dredging}

Dredging occurred in the turning basin of the POA and at the docks during the sampled months, which explains why this noise source was only detected at Cairn Point and Six Mile (Table 2 ). This noise class was difficult to discern from other shipping related noise sources as it involves a tug boat and barge and could be an important contributor in other noise classes such as "unclassed machinery" and "unidentified." Received SPL values reported higher sound amplitudes, particularly in August, at Cairn Point (mean of 121.2 $\mathrm{dB}_{\mathrm{rms}}$ ) than at Six Mile (mean of $107.8 \mathrm{~dB}_{\mathrm{rms}}$; Fig. 4D). However, SEL values indicate the opposite (mean SEL of $127.7 \mathrm{~dB}$ vs. $130.6 \mathrm{~dB}$ ). These discrepancies between metrics reflect 
Count of Sound Pressure Level for Commercial Ships

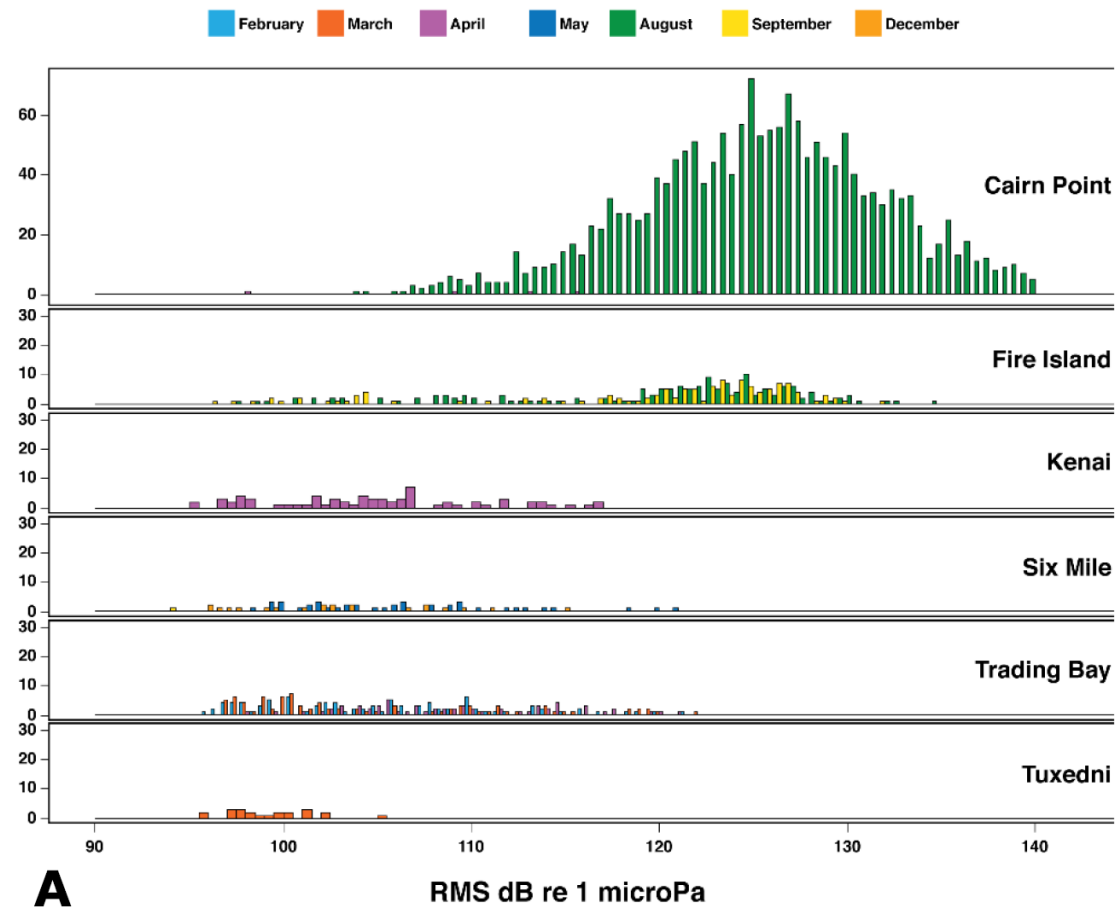

Count of Sound Pressure Level for Jet Aircraft-Non-Fighter

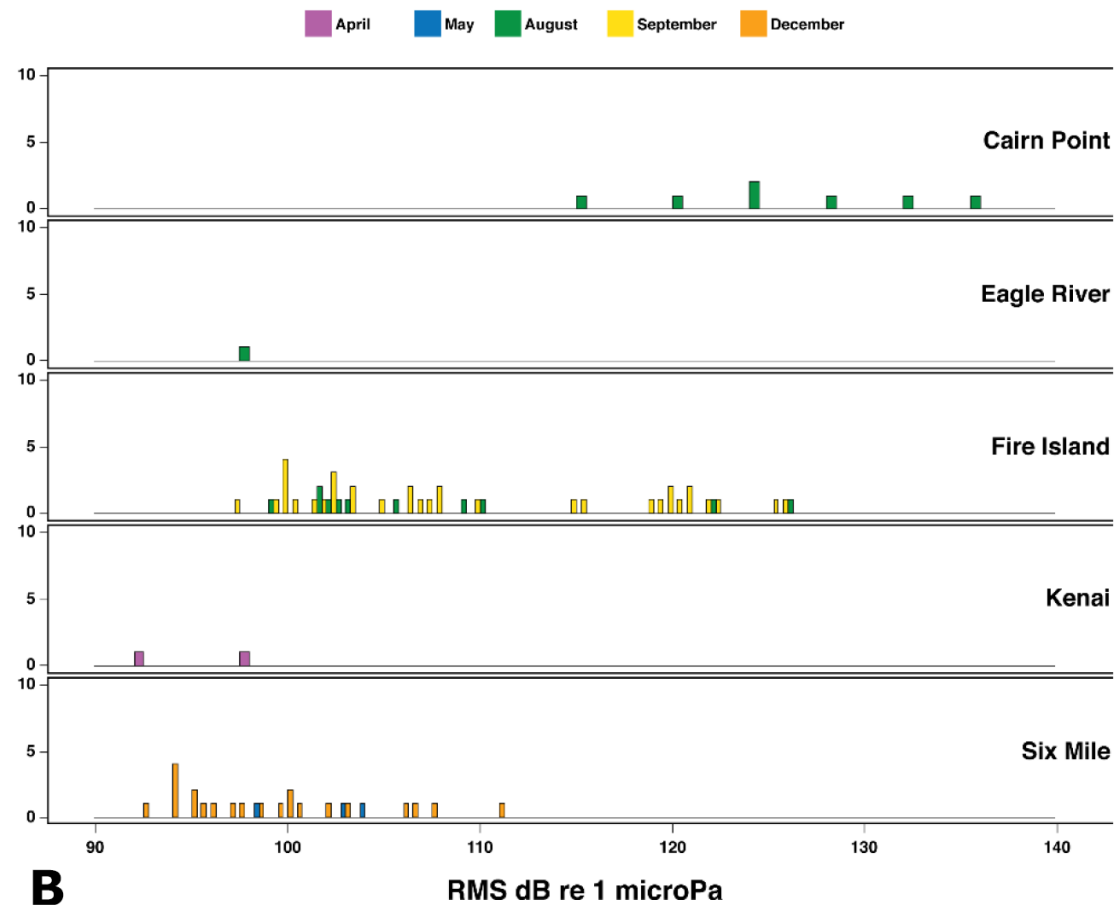

Figure 4.- $\mathrm{SPL}$ in $\mathrm{dB}_{\mathrm{rms}}$ by noise class, month and location from anthropogenic noise events detected in the sampled locations in Cook Inlet, Alaska. Noise classes included are A) commercial ship, B) jet fighter, C) jet aircraft (commercial or military non-fighter), D) dredging, E) outboard motor, F) pile driving, G) unclassed machinery, H) unidentified, I) unidentified clank or bang, and J) unknown down or up sweep. Note that not all noise classes were detected in each location and month sampled. For all other noise classes see Castellote et al. (2016c). longer duration of events at Six Mile than Cairn Point (Fig. 3A), and could be related to the different locations dredged among the sampled months, and different dredging methods used (e.g., both a clam shell and a hopper system were used in the POA during the sampled period) (Anderson ${ }^{15}$ ).

For most events, the peak amplitude fell into the 1/3 octave band centered at $793 \mathrm{~Hz}$ (Fig. 5D). Averaged received spectrum levels for this band exceeded $110 \mathrm{~dB}$ re $1 \mu \mathrm{Pa}^{2} / \mathrm{Hz}$, which is above the beluga hearing threshold (Awbrey et al., 1988), and all the 1/3 octave band levels above this frequency were also above the hearing thresholds (Awbrey et al., 1988; Castellote et al., 2014), therefore beluga hearing and communication may be masked by dredge noise at the locations and months sampled here. The detection of multiple events of dredge noise at Six Mile indicates that belugas are exposed to this noise source even if they avoid the eastern side of the lower Knik Arm, where most of the dredging operations occur. Six Mile SPLs for this non-impulsive source did not exceed $125 \mathrm{~dB}_{\mathrm{rms}}$ but maximum SPLs at Carin Point reached $137.1 \mathrm{~dB}_{\mathrm{rms}}$. It is likely that closer to the dredging area, radiated noise might well exceed 125 $\mathrm{dB}_{\mathrm{rms}}$ across the arm and would therefore expose any beluga that enters or exits Knik Arm to levels of noise exceeding the current behavioral harassment threshold.

\section{Outboard motor}

Outboard motor noise was detected at Eagle River, Cairn Point, Fire Island, and Kenai. Received SPLs varied (mean $107.6 \mathrm{~dB}_{\mathrm{rms}}$, maximum of $131.4 \mathrm{~dB}_{\mathrm{rms}}$; Fig. 4E) and probably reflect the different distances at which these noise sources were detected rather than differences in the noise source itself. In total, there were 48 events detected in three different months, suggesting that outboard motors are often used in Cook Inlet, at least from April to September. However, their acoustic

\footnotetext{
${ }^{15}$ Anderson, J. Chief of Operations at the U.S. Army Corps of Engineers' Alaska District. Personal commun., 25 Nov. 2014.
} 


\section{Count of Sound Pressure Level for Jet Aircraft-Military Fighter \\ May August September December}

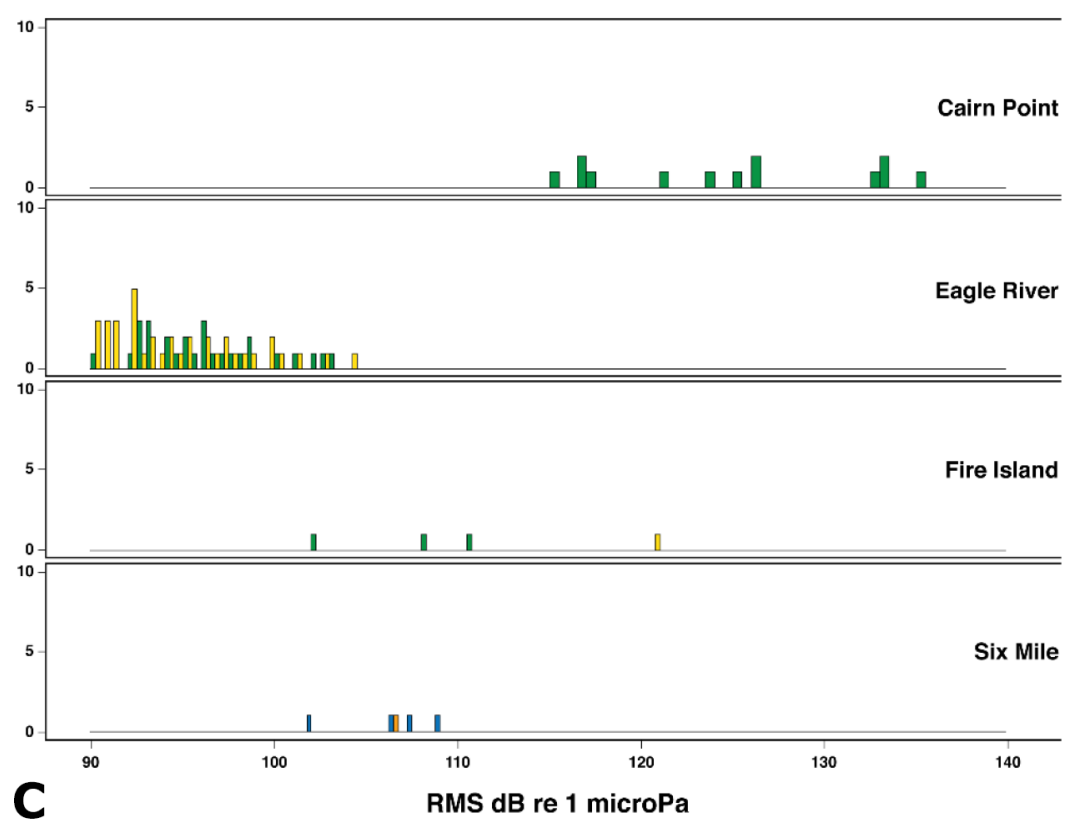

C RMS dB re 1 microP

Count of Sound Pressure Level for Dredging

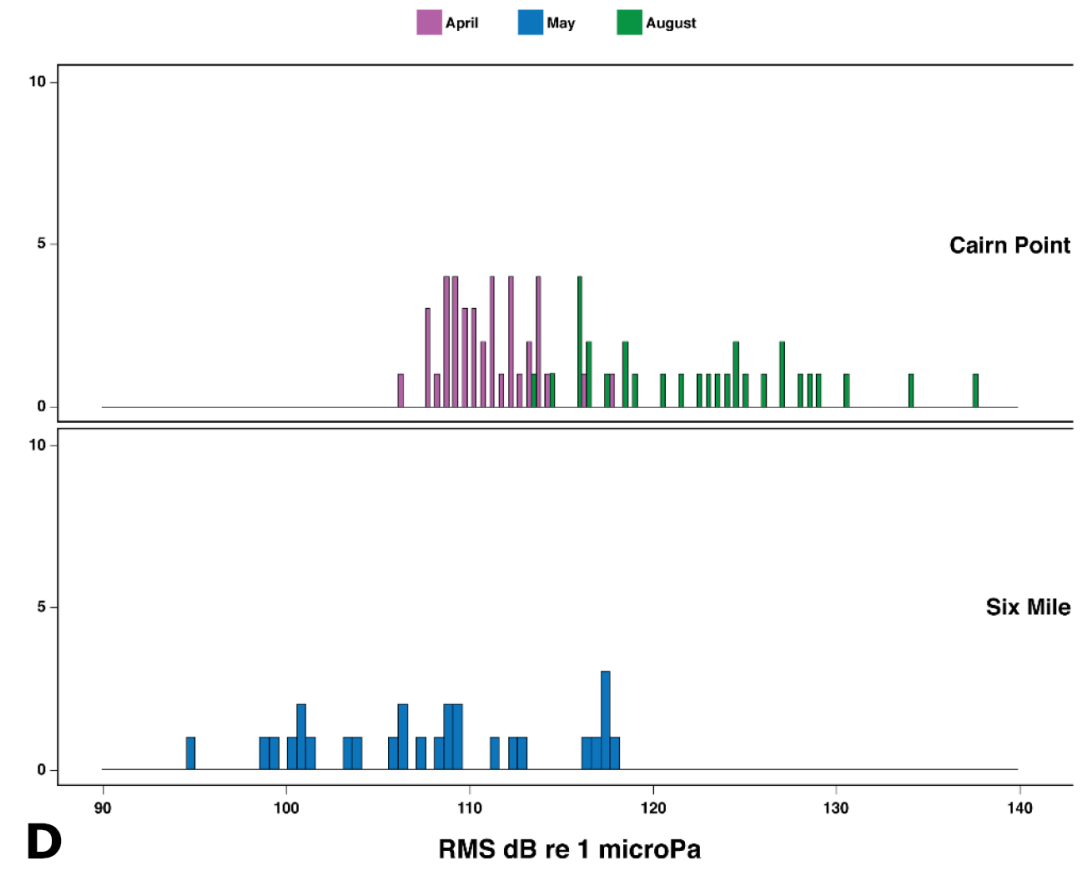

Figure 4.-Continued. disturbance is short-lived, on average 2.5 min (except for Kenai, see below).

Outboard motor noise typically presents strong harmonic contents. This is reflected by the higher number of energy peak values in the $1 / 3$ octave bands centered at $397 \mathrm{~Hz}, 1000$ $\mathrm{Hz}$ and $8000 \mathrm{~Hz}$ (Fig. 5E). Peak 1/3 octave band levels only exceed beluga hearing at $8000 \mathrm{~Hz}$ and higher (Castellote et al., 2014). Because beluga hearing is more sensitive at higher frequencies, this noise source might cause stronger interference to beluga hearing and communication, however, because of its short duration, and low density of occurrence, this acoustic disturbance might not be a concern for Cook Inlet belugas. An exception to this conclusion is Kenai. A total of 21 days in April 2012 were sampled for this study detecting outboard motors with average durations of $2.5 \mathrm{~h}$, and maximum of $6.9 \mathrm{~h}$. When these detections were reviewed, the detection period included what look like multiple outboard motors used concurrently for long periods of time each day. These results suggest intense use of outboard motors in the area throughout the day, at least in April. Small boats and rafts are common at the mouth of Kenai River during the fishing season. The City of Kenai operates four public launch ramps at the mouth of the river, the only ones available in the area, and it is home to many commercial fish processing and cannery operations. Kenai is also a world-class sport fishing area. However, April is too early for most fishing operations, except the eulachon dip net fishery, opening on 1 April, and rafts and boats being tested in preparation for the fishing season $\left(\right.$ Marston $^{16}$ ). We did not sample later months in the season at Kenai, but these results suggest that fishing activities at Kenai River, starting in April, might introduce a strong seasonal acoustic disturbance at this important beluga feeding habitat. Furthermore, the results discussed here should be placed in a behavioral con-

${ }^{16}$ Marston, B. Northern Kenai Peninsula Area Fisheries Biologist, Alaska Dep. Fish Game. Personal comm., 15 March 2016. 
text. The exposure to outboard motor noise, in terms of spectral density or duration, might moderately disturb the acoustic space of belugas, but if belugas are sensitized to this noise source, its presence in the environment could trigger strong behavioral reactions such as spatial displacement. Sensitization occurs when the noise stimulus could generate physiological damage and is recurrently used (Bejder et al., 2009). Cook Inlet belugas have been hunted from small boats operated by outboard motors since the 1930's, and are known to be sensitized to outboard noise (Huntingon, 2000).

\section{Pile Driving}

Impact pile driving noise was detected at three different sites in three different months. Detections at Six Mile in May 2012 correspond to the Cook Inlet Tug and Barge Company's trestle and barge float improvements near the POA. Detections at Fire Island in August 2009 correspond to the POA Marine Terminal Redevelopment Project at the north extension of the port. Neither NMFS nor the U.S. Army Corps of Engineers are aware of any piling activity that corresponds to the single detection of approximately 30 minutes (Fig. 2B) at Kenai in April 2012 (Mahoney $^{17}$ ).

Pile driving activity is a well-studied acoustic disturbance of primary concern for the impact to marine mammals (Dahl et al., 2015). NMFS currently evaluates any application for pile driving in Cook Inlet, with particular concern to potential impact on belugas, and multiple mitigation procedures are requested as part of the permitting process. It is surprising that a pile driving operation was identified in Kenai in April 2012 without any related permit.

The Cook Inlet Tug and Barge Company's operation involved three 12inch steel cylindrical piles and nine 24-inch steel piles. Impact pile driving was detected at a distance of $6 \mathrm{~km}$ (Six Mile) with mean received levels of

\footnotetext{
${ }^{17}$ Mahoney, B. NMFS Alaska Regional Office.
} Personal commun., 14 March 2016.
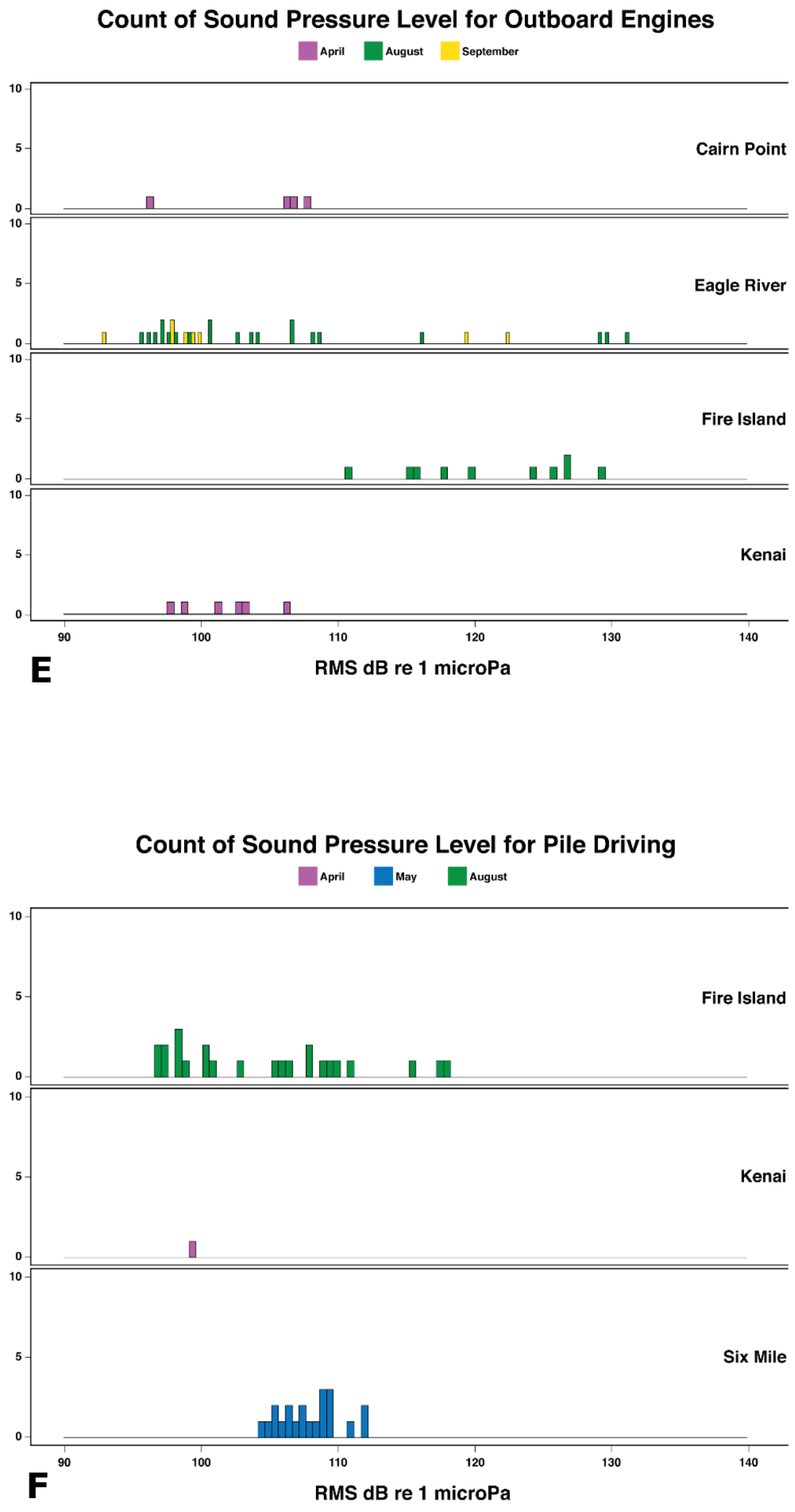

Figure 4.-Continued. 
Count of Sound Pressure Level for Unclassed Machinery

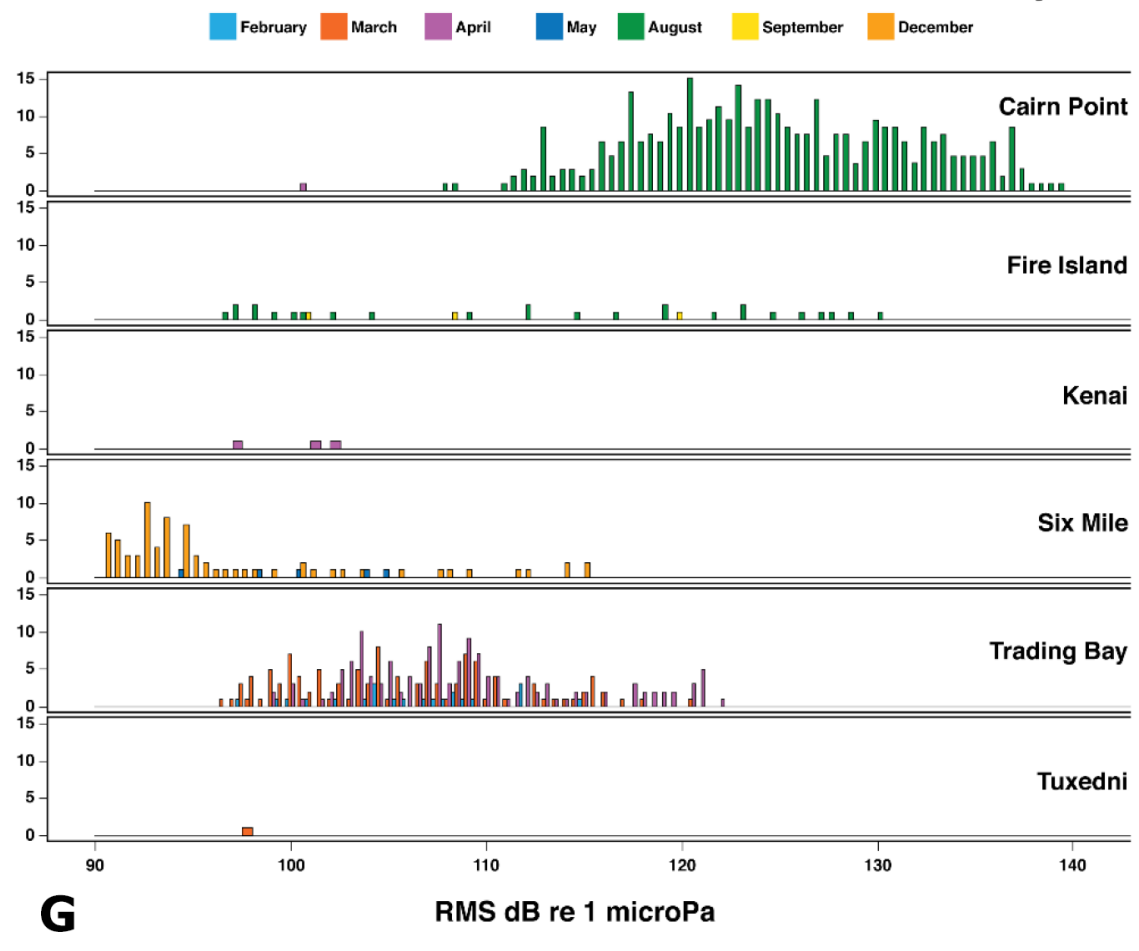

\section{Count of Sound Pressure Level for Unidentified}

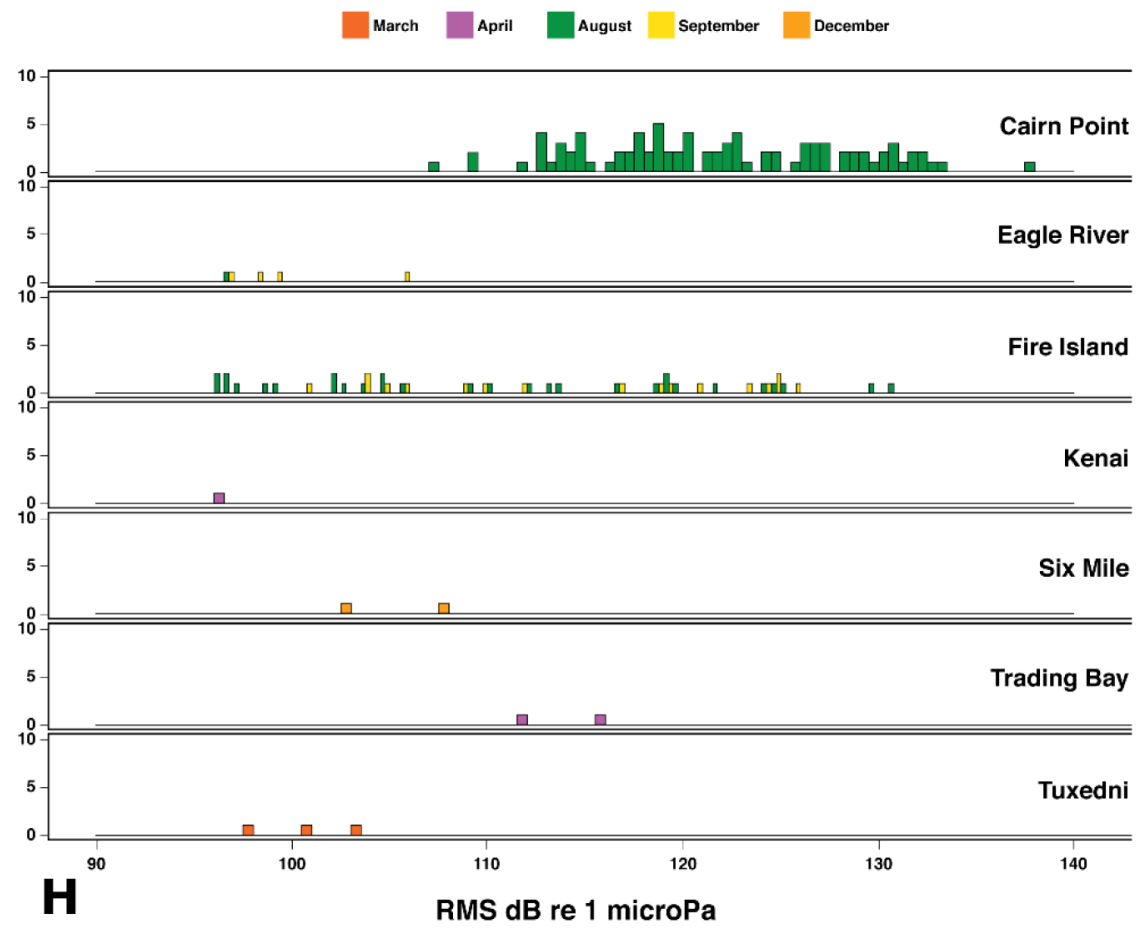

Figure 4.-Continued.
$127.2 \mathrm{~dB}$ peak, $107.4 \mathrm{~dB}_{\text {rms }}$, and 120.4 $\mathrm{dB}$ SEL. Maximum levels reached $134.7 \mathrm{~dB}$ peak, $111.5 \mathrm{~dB}_{\mathrm{rms}}$, and 141.1 dB SEL (Fig. 4F).

The north extension of the POA involved impact piling of 14-inch by 90-ft long, steel H-piles. Piling was detected $18 \mathrm{~km}$ away (Fire Island) with mean received levels of $128.1 \mathrm{~dB}$ peak, $103.1 \mathrm{~dB}_{\mathrm{rms}}$, and $118.6 \mathrm{~dB}$ SEL, reaching maximums of $131.4 \mathrm{~dB}$ peak, $117.2 \mathrm{~dB}_{\mathrm{rms}}$, and $140.8 \mathrm{~dB}$ SEL (Fig. $4 \mathrm{~F})$.

Even if most of the acoustic energy radiated by the pile strikes was at low frequencies (below $1000 \mathrm{~Hz}$; Fig. 5F), received spectral levels for both piling operations exceeded beluga hearing thresholds at the $4 \mathrm{kHz}$ band and higher (Castellote et al., 2014). Vibratory pile driving was also used in these two operations but was not identified in the recordings and was likely classified as unclassed machinery. For the POA piling, a sound source verification was made in 2008, obtaining a worst case source level of $200 \mathrm{~dB}$ (Scientific Fishery Systems, 2009). Impact piling propagation loss would correspond to $22.8 \times \log$ (range in $\mathrm{m}$ ) to obtain our received levels at Fire Island. Assuming constant propagation loss conditions across the arm, and worst case for source level for the impact pile driving, the $125 \mathrm{~dB}$ isopleth distance would be situated just passed the east shoreline across the port $(2910 \mathrm{~m})$ at the narrower part of the arm. Therefore, most of the width of the arm was likely ensonified to levels exceeding the behavioral threshold during this pile driving operation. A second acoustic study was made in 2009 yielding similar source levels, but the obtained propagation loss conditions were much less restrictive, 16.4 $\mathrm{x} \log$ (range in $\mathrm{m}$ ) (Širović and Saxon Kendall ${ }^{5}$ ). Using this propagation loss, the $125 \mathrm{~dB}$ isopleth would be reached at $37.5 \mathrm{~km}$ from the source.

These results suggest that sound propagation conditions, at least in the lower region of Knik Arm, are very complex and difficult to predict. But the concerning thought here is that the acoustic disturbance generated, beyond 
the injury and behavioral harassment levels required to be monitored, often includes a vast region of beluga critical habitat. This is of special concern in constrained habitat areas such as Knik Arm. No passage might remain free of acute acoustic disturbance exceeding the behavioral threshold of $125 \mathrm{~dB}$ for transiting belugas, where pile driving operations have been ongoing for multiple years (2006-11, and 2016) as part of the POA Marine Terminal Redevelopment Project. The more recent POA modernization project, where months of pile driving are expected for multiple consecutive seasons starting in 2020, is one more case where unavoidable behavioral harassment, and its cumulative effects, should be taken into consideration.

\section{Sub-bottom Profiler}

Transducer generated sweeps from a sub-bottom profiler were detected at the Fire Island deployment location for more than 9 consecutive hours on 19 August 2009 (154 dB peak, 128 $\mathrm{dB}_{\text {rms }}, 173 \mathrm{~dB}$ SEL) and in Kenai for 3 hours on 1 April 2012 (124 dB peak, $105 \mathrm{~dB}_{\mathrm{rms}}, 119 \mathrm{~dB} \mathrm{SEL}$ ). Mean sweep duration was $0.042 \mathrm{sec}$ (standard deviation 0.015 ) but often with intense reverberation lasting up to $0.2 \mathrm{~s}$, and the sweep started at $1 \mathrm{kHz}$ and ended at $4.5 \mathrm{kHz}$, corresponding with the $1 / 3$ octave bands of highest received spectral levels. Received spectral levels at these frequencies all exceeded beluga hearing thresholds (Awbrey et al., 1988; Castellote et al., 2014). The activity at Fire Island was related to a survey for a marine renewable energy project; however, the survey in Kenai has not been identified by NMFS. Received levels reported at Fire Island, considering that time intervals between sweeps are included in the SPL calculation, suggest that this activity ensonified a wide area with levels exceeding the behavioral harassment threshold of $125 \mathrm{~dB}_{\mathrm{rms}}$. Furthermore, this noise class also suffered clipping, another reason to consider received levels reported here as very conservative.

This noise class, together with some events of commercial ship noise, are
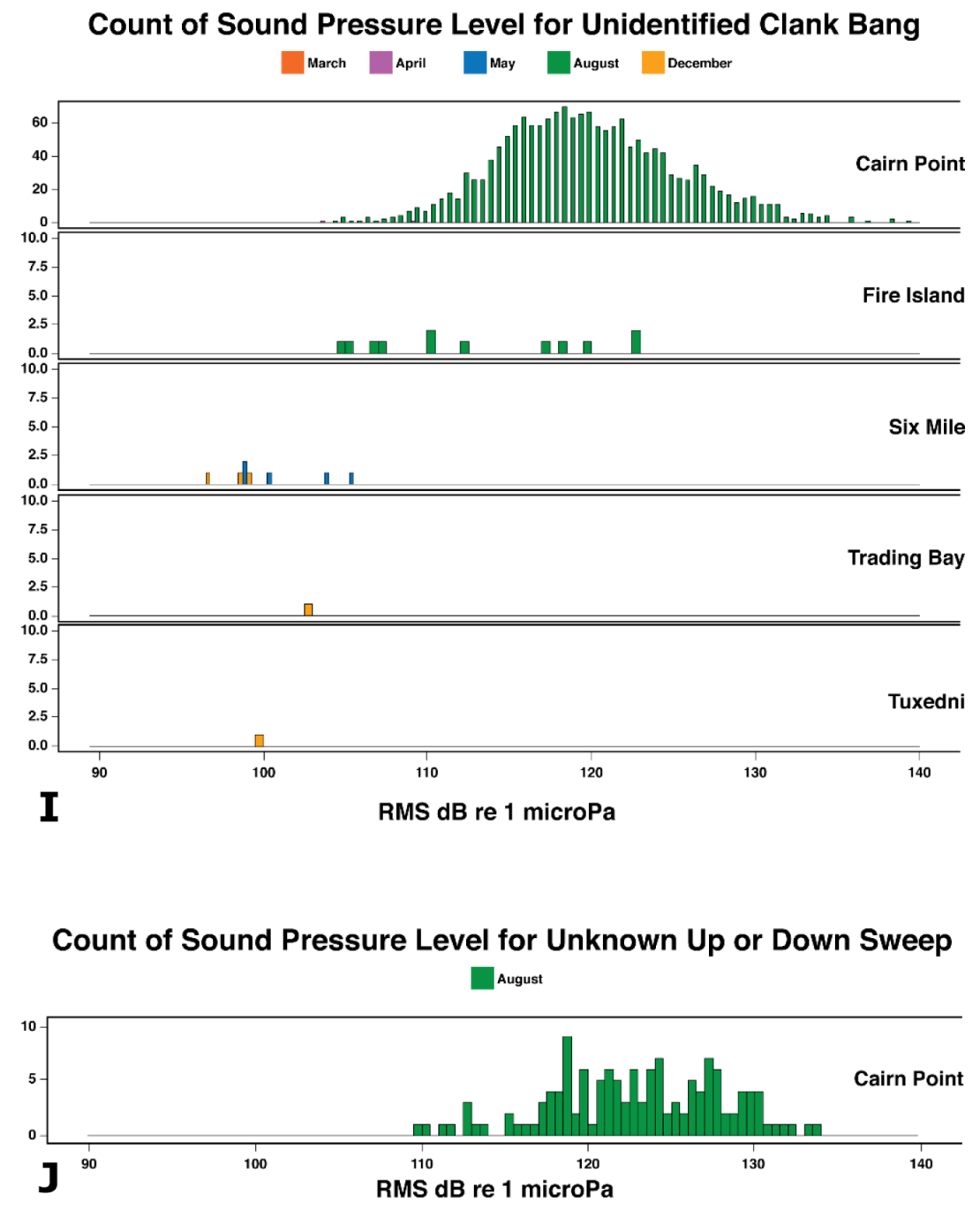

Figure 4.-Continued.

the highest amplitude anthropogenic noises detected throughout the data analyzed in this study, highlighting the relevance of the acoustic disturbance generated by sub-bottom profilers.

\section{Helicopter and Propeller Aircraft}

These two sources of noise had transient signatures that did not dominate the soundscape in the months and areas sampled (Table 2), thus, they are not discussed here. For details on these detections see Castellote et al. ${ }^{13}$.

\section{Unclassed or Unidentified Sources}

The amount and prevalence of unidentified or unclassed noise events was surprisingly high in our dataset. As in any environmental acoustic study, unknown transient sounds are detected and cannot be identified without concurrent visual information. However, in Cook Inlet, many of these unknown signals are repetitive, very stereotyped (i.e., easily distinguishable with unique acoustic structure), and often repeatedly detected in the same locations for long periods of time. For example, $7.5 \%$ of the detections at Cairn Point were assigned to unclassed machinery with the longest durations of any anthropogenic event (mean duration of $6.1 \mathrm{~h}$ ), and $50.7 \%$ were assigned to unidentified clank or 
Commercial ship

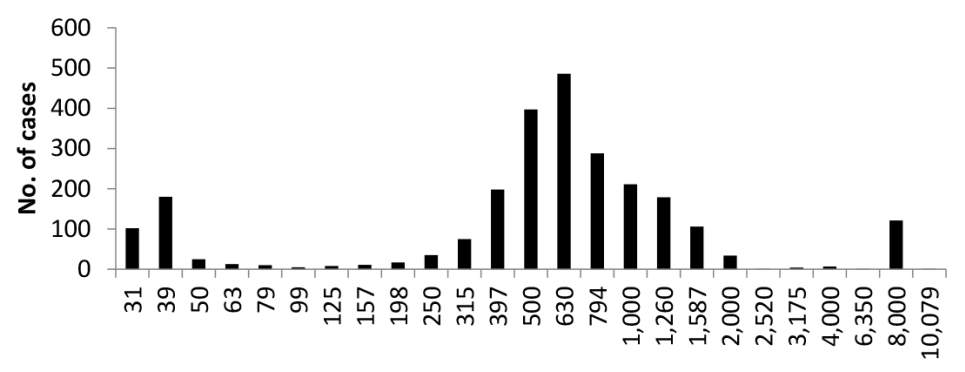

A
Jet aircraft military fighter

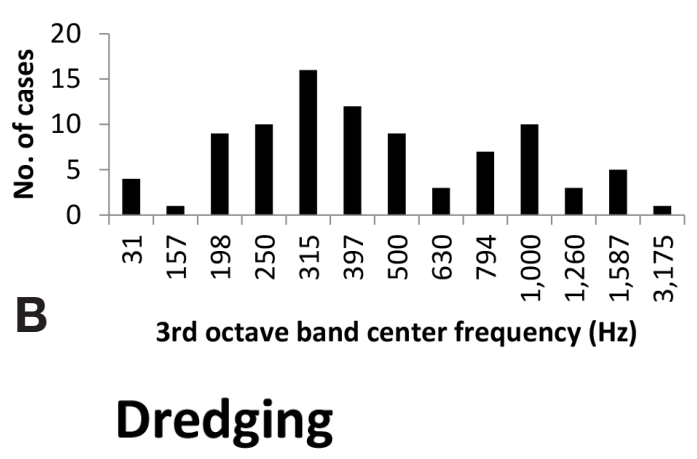

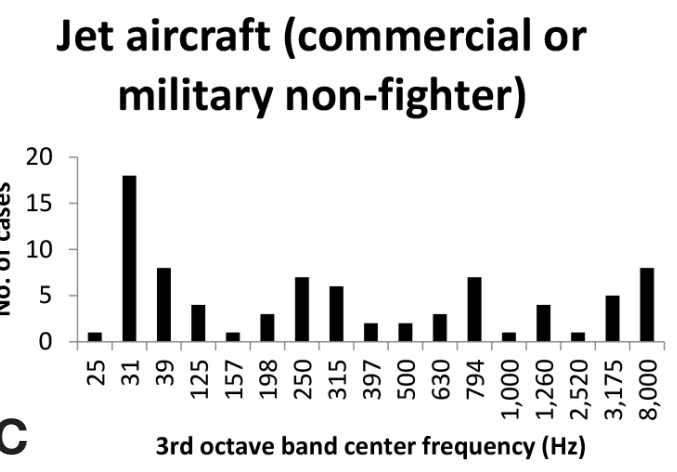

Outboard motor

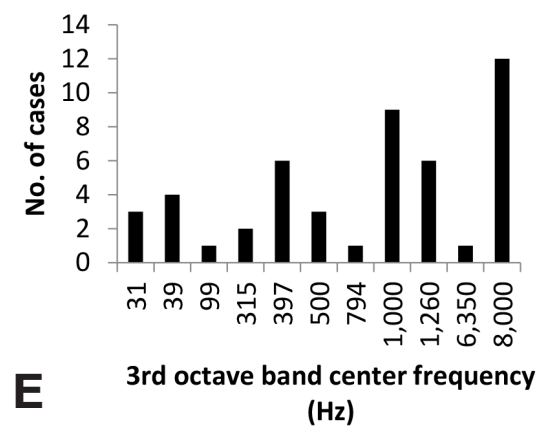

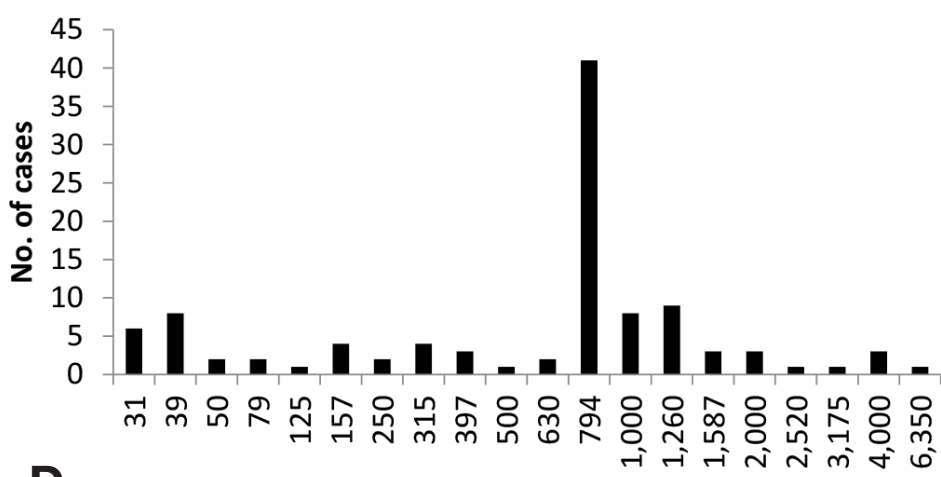

3rd octave band center frequency $(\mathrm{Hz})$

Pile driving

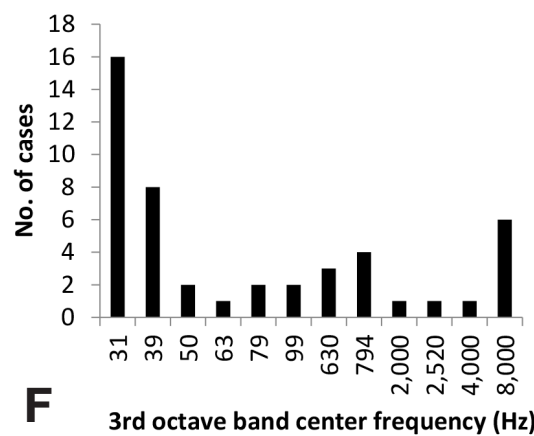

Figure 5.- Histograms with counts of $1 / 3$ octave bands containing the maximum amplitude (peak band) per noise class. This histogram provides an overview of the dominant $1 / 3$ octaves for each noise class identified in the sampled locations in Cook Inlet, Alaska. Noise classes included are, A) commercial ship, B) jet aircraft military fighter, C) jet aircraft (commercial or military nonfighter), D) dredging, E) outboard motor, and F) pile driving. For all other noise classes see Castellote et al. (2016c).

bang noise. All of these unclassed or unidentified noises exceeded beluga hearing thresholds at frequencies 500 $\mathrm{Hz}$ and higher (Awbrey et al., 1988; Castellote et al., 2014).

Together with Cairn Point, Trading Bay and Six Mile had the highest percentages of unclassed machinery and unidentified noise $6 \%$ and $53.9 \%$ of the total duration of anthropogenic noise events, respectively), and higher SPLs (means of $124.7 \mathrm{~dB}_{\mathrm{rms}}$ and 123.1 $\mathrm{dB}_{\text {rms }}$ respectively, with a maximum reaching our recorders' upper limit of $144 \mathrm{~dB}_{\mathrm{rms}}$, Fig. $4 \mathrm{G}$ and $4 \mathrm{H}$ ). Cairn Point and Six Mile are exposed to most of the noise derived from the industrial activities at the port facilities, the related shipping, as well as dredging activities in the port basin. Trading Bay included recurrent unidentified 
Count of Sound Exposure Level for Commercial Ships

February March April \} \text { May } \square \text { August September December }

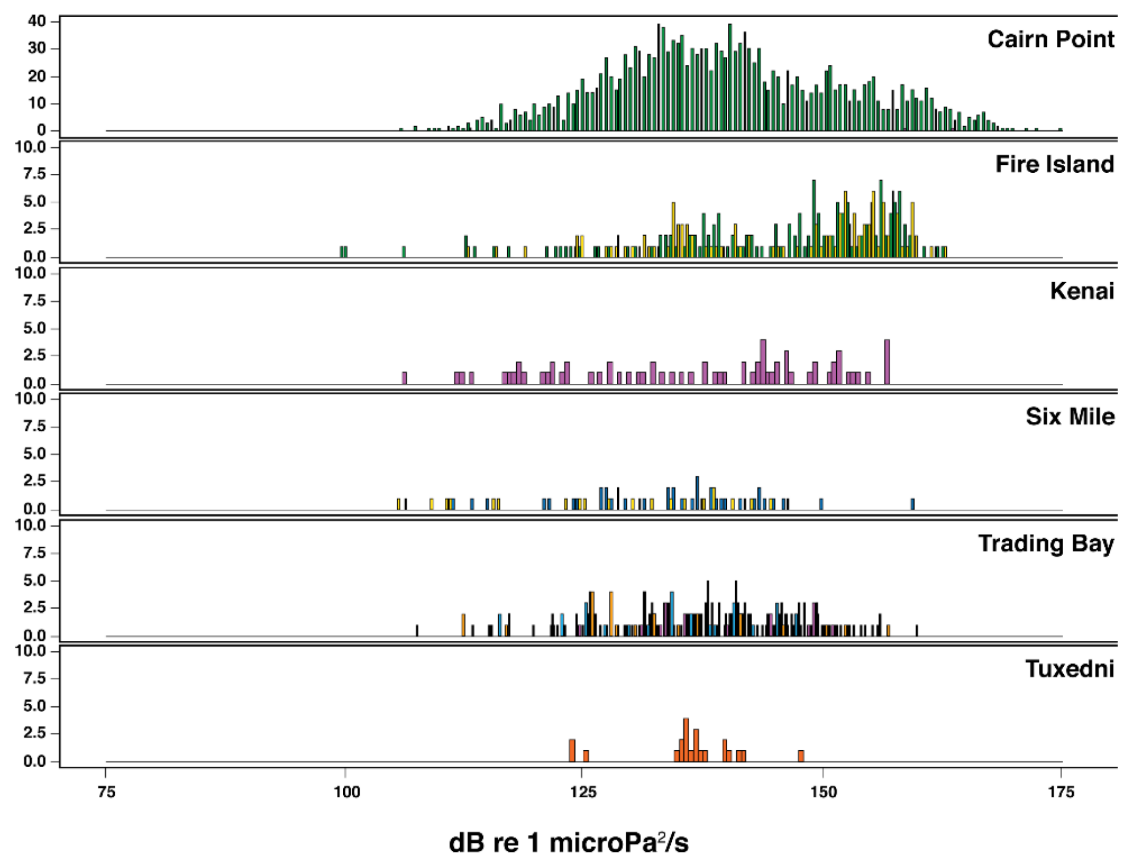

Figure 6.- - Histogram with count of ship noise events per received level in SEL (dB re $1 \mu \mathrm{Pa}^{2} / \mathrm{s}$ ) showing the distribution of SEL, per month and location, from all events of commercial shipping noise detected in the sampled locations in Cook Inlet, Alaska. For all other noise classes see Castellote et al. (2016c).

noise with mean duration of $2 \mathrm{~h}$ that could be related to the oil and gas production activities from the multiple platforms and underwater pipelines in that location.

Similar to unclassed machinery and unidentified noise, unidentified clank or bang noise was a very prevalent noise class at Cairn Point, with the highest percentage of time of the total duration of anthropogenic noise events in this location (50.7\%) and with mean longest sequence duration (Fig. 3) at Cairn Point and Fire Island. Some clank or bang signals appeared to be a cluster of multiple discrete impulsive signals, other times this noise was received as a rapid succession of multiple signals that could be the consequence of a sound propagation effect (e.g., multipath arrival) or a rapid iteration of the same type of percussive sound. This noise class often occurred concurrently with ship noise and might be related to shipping op- erations, where tug boats assist commercial vessels or barges and impact sounds are generated. The highest amplitude events occurred at Cairn Point (mean of $142.7 \mathrm{~dB}$ peak, maximum of $147.9 \mathrm{~dB}$ peak, Fig. 4I), followed by Fire Island (mean of 135.6 $\mathrm{dB}$ peak, maximum of $147.9 \mathrm{~dB}$ peak, Fig. 4I), and are likely a reflection of the proximity of the recorders to the area where these noises are generated, likely the shipping route. Clipping was also important for this noise class, therefore reported SPLs here are conservative.

Unknown up or down sweep noise was a very prevalent event $(26 \%$ of all noise events) that occurred exclusively at Cairn Point (data from August 2010) with mean SPL of $117.7 \mathrm{~dB}_{\text {rms }}$ and maximum of $135 \mathrm{~dB}_{\text {rms }}$ (Fig. 4J). This noise class was concurrent with unclassed machinery and often occurred during changes in intensity of the related machinery noise or what was be- lieved to be a reduction in rpm. It is not believed to originate from dredging operations (Anderson ${ }^{14}$ ), but because it was only detected in this location it was likely related to port activities.

\section{Natural Background Noise in Cook Inlet}

Our approach was to process the data to identify the periods with minimal presence of anthropogenic noise, however, inspection of the sound file selections corresponding to the higher sound amplitude periods confirmed that all the upper inlet locations included self-noise contamination (flow noise and debris hitting the mooring) in all months. Fire Island, Six Mile, and Cairn Point were the most affected locations by flow noise. The SPL histograms in Figure 7 show abundant RL conditions in the range of 120-130 $\mathrm{dB}_{\mathrm{rms}}$ that correspond to tidal cycle periods of high current, when selfnoise was predominant.

Background noise values for periods clean of anthropogenic noise were considered to be the natural background reference for each location for comparisons with anthropogenic noise contribution. Table 3 summarizes SPL results for each location and month. Mean $\mathrm{dB}_{\mathrm{rms}}$ shown in Table 3 are below $120 \mathrm{~dB}_{\text {rms }}$ for all locations, even if some results suffered contamination by self-noise. Highest mean SPL reached $117.8 \mathrm{~dB}$ in Fire Island with $53.7 \%$ of the time exceeding $120 \mathrm{~dB}_{\text {rms }}$, but this location is likely the one exposed to highest currents. If we exclude the three locations most contaminated by self-noise, SPL were below $120 \mathrm{~dB}$ for $94-100 \%$ of the time.

Percentile analysis reflected how daily noise varied considerably in Cook Inlet (Fig. 7). Differences greater than $40 \mathrm{~dB}$ can be observed within all sites from the quietest ( $10^{\text {th }}$ percentile) to the loudest periods ( $90^{\text {th }}$ percentile), which highlights how easily baseline background noise measurements in Cook Inlet can be misinterpreted if the full tidal cycle is not included in the sample and if self-noise contamination induced by high currents and vegetative debris is not considered. 
Fire Island, Six Mile, and Cairn Point, the three locations of higher influence by currents, showed considerably higher noise levels across the full frequency range, but in particular in the range $0-1000 \mathrm{~Hz}$ and for the 50th and upper percentiles. Spectrum levels in these three locations never got close to those of Eagle Bay or Tuxedni Bay, the quietest locations, except for the highest frequencies, above $10 \mathrm{kHz}$. Cairn Point's spectral curves showed higher variability from $30 \mathrm{~Hz}$ to $1000 \mathrm{~Hz}$ suggesting the influence of low level, recurrent anthropogenic noise which was likely missed during the manual processing of the raw data.

The contribution of natural noise generated by high currents in upper Cook Inlet (air bubbles in the upper water column and breaking waves on shore, mud, and sand bars) will only affect the $0-1 \mathrm{kHz}$ frequency range $\left(\mathrm{HDR}^{6}\right)$. Belugas have poor hearing below $1 \mathrm{kHz}$, with thresholds in the 100-120 dB range (Awbrey et al., 1988) that are above the noise levels obtained in this study. Even the highest levels of natural background noise (i.e. without human contribution) shown in Figure 7 never exceeded hearing thresholds for belugas (Awbrey et al., 1988; Castellote et al., 2014). Therefore, the contribution of natural noise by high currents has little relevance, if any, when considering the potential for masking on Cook Inlet beluga hearing and communication signals.

From this perspective, then, for belugas, the natural soundscape (i.e., without human influence) of Cook Inlet may not be a noisy environment. The upper Cook Inlet is considered a naturally high amplitude environment and thus acoustically poor (NMFS, 2008; $\mathrm{NMFS}^{7}$ ), but natural background noise might only be above beluga hearing thresholds during particular periods of elevated ambient noise (e.g., exceptionally strong current periods, storms, etc.). When SPL results from the locations in Cook Inlet that were minimally affected by self-noise (e.g., Eagle River, Tuxedni Bay, Trading Bay, Kenai River) are compared to other published results on underwater ambient noise, these are well below spectral levels reported for exceptionally quiet periods in open waters (Rolland et al., 2012), abyssal trenches (Barclay and Buckingham, 2014), or the Southern Ocean (Menze et al., 2017). Spectra and received SPLs for quiet locations in Cook Inlet are also below the estimated natural background noise levels in Saguenay Fjord in the St. Lawrence estuary, Can., which is critical habitat for another endangered beluga population (Gervaise et al., 2012; COSEWIC, 2014).

Interestingly, ice noise was not identified in any of the data sets analyzed for this study. Little is known on the noise production of new ice or first year ice. The elevated noise levels in some frequency bands identified during periods of natural background noise levels in winter (e.g., Fig. 7) could be related to noise generated by this thin ice. Further research is needed to better understand the effect of ice presence in the natural background noise conditions in Cook Inlet.

\section{Noise Management Considerations}

The results of our study support the thesis that anthropogenic noise carries a threat of high concern to the recovery of the Cook Inlet beluga population (NMFS, 2016). Recognizing current efforts to mitigate impacts to belugas from close-range noise sources in Cook Inlet (e.g., seismic surveys or pile driving), this study highlights the prevalence and diversity of many other anthropogenic noise sources occurring across a wide spatial scale within the critical habitat of Cook Inlet beluga whales. The acoustic characteristics of most of the detected noise events in this study have the potential to mask beluga hearing at certain frequencies and also their communication, and some exceed the current NOAA behavioral harassment thresholds on a daily basis.

Our results on natural background noise levels (i.e., without anthropogenic contribution or recording self-noise) do not support the current approach of using an elevated behavioral harassment threshold of $125 \mathrm{~dB}_{\mathrm{rms}}$ for non-impulsive noise exclusively in the upper inlet. This approach, allowing a $+5 \mathrm{~dB}$ over the $120 \mathrm{~dB}$ threshold defined by NMFS, has been applied to industrial operations since 2009, such as the POA Marine Terminal Redevelopment Project (vibratory piling) or Apache Alaska Corp. 3D seismic surveys (noise from vessels involved in the activity). $\mathrm{A}+5 \mathrm{~dB}$ difference in the threshold can be translated into an important decrease in the isopleth distance to be considered for the onset of behavioral harassment. This threshold appeals to stakeholders as it implies smaller risk of shut downs, power downs, or takes, and reduced areas to be covered visually for mitigation purposes.

Behavioral reactions need to be considered when background noise departs from natural noise conditions. The $120 \mathrm{~dB}$ threshold defined by NMFS for non-impulsive sources originated from research on migrating gray whales, Eschrichtius robustus (Malme et al., 1983; Malme et al., 1984). These authors documented behavioral responses to industrial noise playbacks depending on the characteristics of the signal-to-background noise conditions, comparing the playback received levels to the background noise levels just before and after the exposure. Reactions often occurred at ranges where the estimated level of the playback was equal to the local background noise level.

Both the work by Malme et al. and the threshold defined by NMFS are based on acoustic disturbances above natural ambient noise conditions and not from already altered acoustic environments which include anthropogenic noise sources. The background noise level to be considered for behavioral responses of belugas in Cook Inlet should correspond to the quiet undisturbed natural conditions, rather than conditions when other anthropogenic activities are altering the background noise levels (even if these are common). Similarly, inflated background noise levels due to recording artifacts, such as self-noise, from the often high current conditions in Knik Arm should 


\begin{tabular}{|c|c|c|c|c|c|c|c|c|c|}
\hline Location & Eagle River & Six Mile & Six Mile & Fire Island & Fire Island & Cairn Point & Trading Bay & Kenai River & Tuxedni Bay \\
\hline Month & Aug-Sep 2010 & Dec 2011 & May 2012 & Aug 2009 & Sep 2009 & $\begin{array}{l}\text { Aug 2010, } \\
\text { Apr } 2011\end{array}$ & Feb-Apr 2012 & Apr 2012 & Mar 2012 \\
\hline n (hours) & 74.3 & 63.7 & 42.4 & 52.5 & 75.1 & 31.1 & 70.9 & & 701.2 \\
\hline Mean dB & $97.9+/-5.8$ & $112.6+/-9.4$ & $116+/-10.1$ & $117.3+/-8.8$ & $117.8+/-8.3$ & $114.3+/-6.1$ & $108.3+/-8.3$ & $102.8+/-5.5$ & $100.2+/-3.8$ \\
\hline $\operatorname{Max} \mathrm{dB}$ & 131.9 & 134.7 & 136.7 & 134.2 & 136.5 & 142.5 & 126.5 & 118.2 & \\
\hline Min $\mathrm{dB}$ & 95.2 & 95.3 & 95.7 & 95.5 & 95.6 & 99.3 & $\begin{array}{l}94.9 \\
66.8\end{array}$ & 95.0 & \\
\hline$<120 \mathrm{~dB}$ & 72.6 h $(97.6 \%)$ & 48.7 (76.5\%) & $25.6(60.4 \%)$ & 20.7 (39.4\%) & 28.4 (37.9\%) & 26.7 h (85.8\%) & (94.3\%) & $34.9(100 \%)$ & $70.2(100 \%)$ \\
\hline $120-125 \mathrm{~dB}$ & $0.8 \mathrm{~h}(1.1 \%)$ & $8.6(13.6 \%)$ & $8.0(18.8 \%)$ & $25.8(49.1 \%)$ & $40.3(53.7 \%)$ & 3.0 h $(9.7 \%)$ & $4.0(5.6 \%)$ & 0 & 0 \\
\hline$>125 \mathrm{~dB}$ & $0.9 \mathrm{~h}(1.3 \%)$ & $6.3(10 \%)$ & $8.8(20.8 \%)$ & $6.0(11.5 \%)$ & $6.4(8.5 \%)$ & $1.4 \mathrm{~h}(4.5 \%)$ & $0.1(0.1 \%)$ & 0 & 0 \\
\hline
\end{tabular}

not be considered as representative of the natural environment.

Our upper inlet results show that natural background noise SPL values are below $120 \mathrm{~dB}$ in all sampled locations for most of the sampled time, except at locations exposed to strong currents, and mean SPLs are below $120 \mathrm{~dB}$ in all locations (Table 3). Therefore, the increased behavioral harassment threshold, by $+5 \mathrm{~dB}$, for non-impulsive noise in the upper Cook Inlet is not justified.

Two recent studies support the notion that upper Cook Inlet background noise is not as elevated as previously described. First, Burgess (2014) measured background noise levels in Turnagain Arm, an area within beluga critical habitat, with previously no reference for noise levels due to the difficulty of monitoring in the shallow waters, the highly dynamic bathymetry of the area, and the presence of extreme bore tides. Based on drifting recordings over a relatively short time period (40 sec to $4 \mathrm{~min}$ ) in the range $19 \mathrm{~Hz}$ to $9.3 \mathrm{kHz}$, Burgess (2014) reported an SPL range from a low $74 \mathrm{~dB}$ at slack tide to a high $108 \mathrm{~dB}$ at flood tide. Second, Austin et al. (2016) measured background noise in the range of $10 \mathrm{~Hz}$ to $64 \mathrm{kHz}$ during 3-day deployments at 2 POA monitoring locations, on the dock and $0.5 \mathrm{~km}$ off the dock, while routine port activities occurred, and reported median SPL of 117 and 122.2 dB. However, mean SPL for the same periods were 138 and $136 \mathrm{~dB}$, respectively, highlighting the strong influence of transient elevated sound periods from routine POA activities on mean SPL values.
Austin et al. (2016) stated that dominant sound sources, from dredging and tugboat activities, occurred throughout the recording. They also reported periodic bursts of elevated sound levels likely caused by flow noise during maximum current flow, and brief peaks of broadband, high amplitude sounds attributed to tug activities and other normal vessel activities at the port, which matches our unidentified clang or bang class. Interestingly, high sound levels with tonal structure were attributed by these authors to dredging noise at the north end of the port. These signals might be the same ones we classified in our study as unknown up or down sweeps that were detected only at Cairn Point.

The results obtained at Cairn Point are particularly concerning. Cumulative effects of multiple sources of noise in this area of Knik Arm should be taken into consideration when evaluating threats and lack of recovery for Cook Inlet belugas, in particular negative effects related to spatial displacement. Results from Cairn Point represented some of the highest anthropogenic noise levels, prevalence, and diversity of both identified and unidentified noise sources.

Acute noise disturbance was caused by pile driving operations from several projects: the multi-year Marine Terminal Redevelopment Project, and maintenance and repairs of damage from ice at the POA, Port McKenzie, and the tug and barge facilities. These acute disturbances were combined with chronic noise from the regular shipping operations from both port facilities and the seasonal dredging of $\sim 1,650,000 \mathrm{~m}^{3}$ of silt required to maintain an operational depth of $-35 \mathrm{ft}$ at the POA (Hoffman, 2012).

Cumulatively, these factors result in a consistently high acoustic disturbance of the lower Knik Arm habitat. Using an elevated behavioral threshold of $125 \mathrm{~dB}_{\mathrm{rms}}$ for non-impulsive noise sources should be reconsidered. Permit applications are typically considered on a case-by-case basis, but the spatial and temporal overlap among activities in our results indicate that the cumulative or additive increase in noise disturbance should be factored into the permitting process.

As part of the critical habitat designation (NOAA, 2011), NMFS defined an exclusion zone covering the POA and waters of Knik Arm in front of the port (i.e., turning basin; depicted in Figure 1). This decision was based on impacts to national security, because the POA supports certain military functions and requirements that cannot be met elsewhere in Alaska. Also, certain non-military functions that support the operational readiness of the port, such as maintenance dredging, could impact military operations if they were delayed or otherwise impacted by the designation.

Following the requirements of Section 4 of the Endangered Species Act $\left(\mathrm{USFWS}^{18}\right)$, based on best scientific and commercial data, NMFS determined that the benefits of this exclusion zone outweighed the benefits to belugas without the zone. However,

${ }^{18}$ USFWC (U.S. Fish and Wildlife Service). Endangered Species Act, Section 4. Available online at https://www.fws.gov/endangered/lawspolicies/section-4.html. 

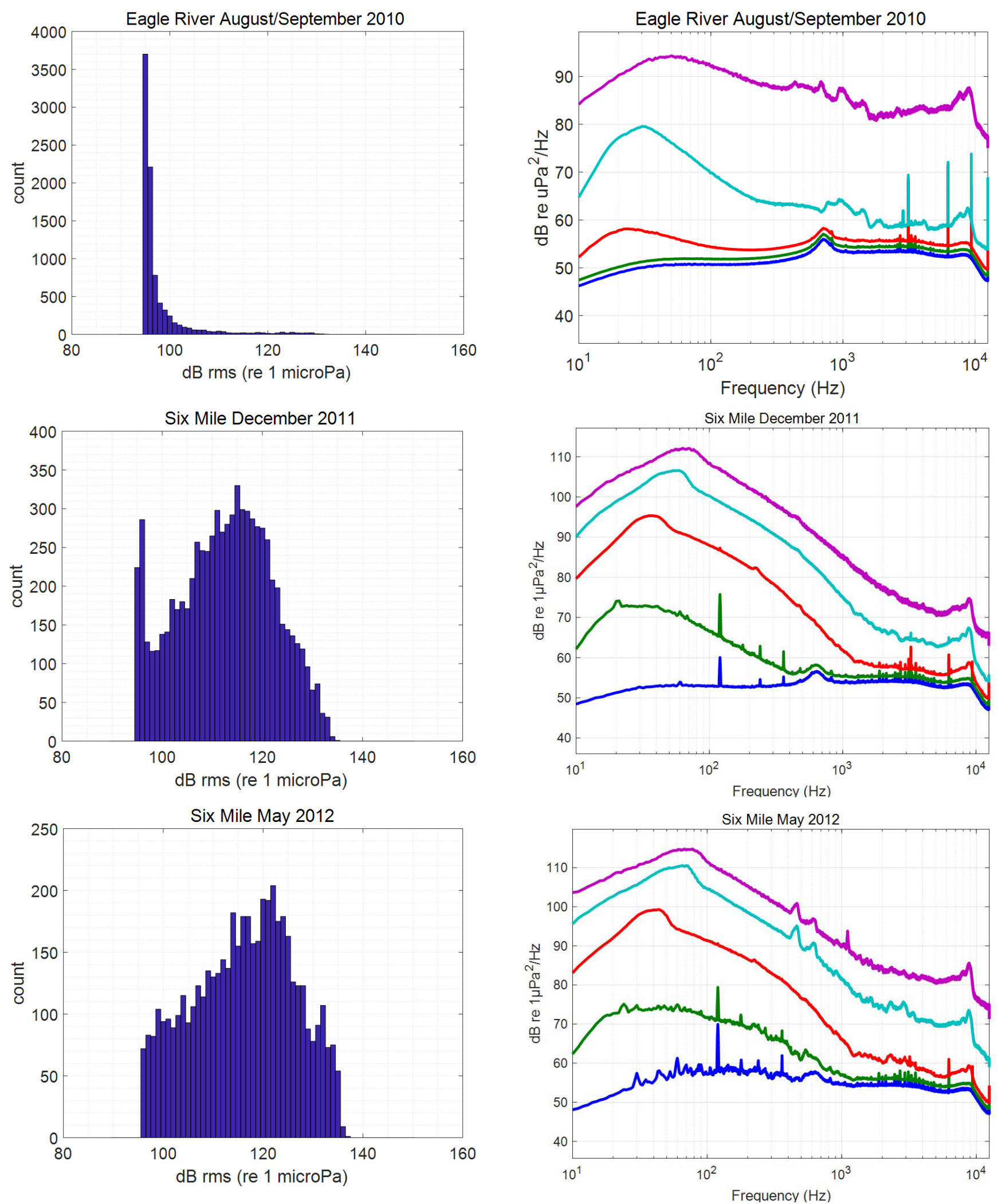

Figure 7.-Background noise metrics for each mooring location and month, obtained from periods without any visible anthropogenic noise signal in the spectrogram analysis. Left: Histograms of Sound Pressure Level (SPL) over the full band of the recording $(0.01-12.5 \mathrm{kHz})$ in $1 \mathrm{~dB}$ bins for 5 min periods. Right: Power spectral density percentiles $($ blue $=1 \%$, green $=10 \%$, red $=50 \%$, light blue $=90 \%$, and purple $=99 \%$ ). 

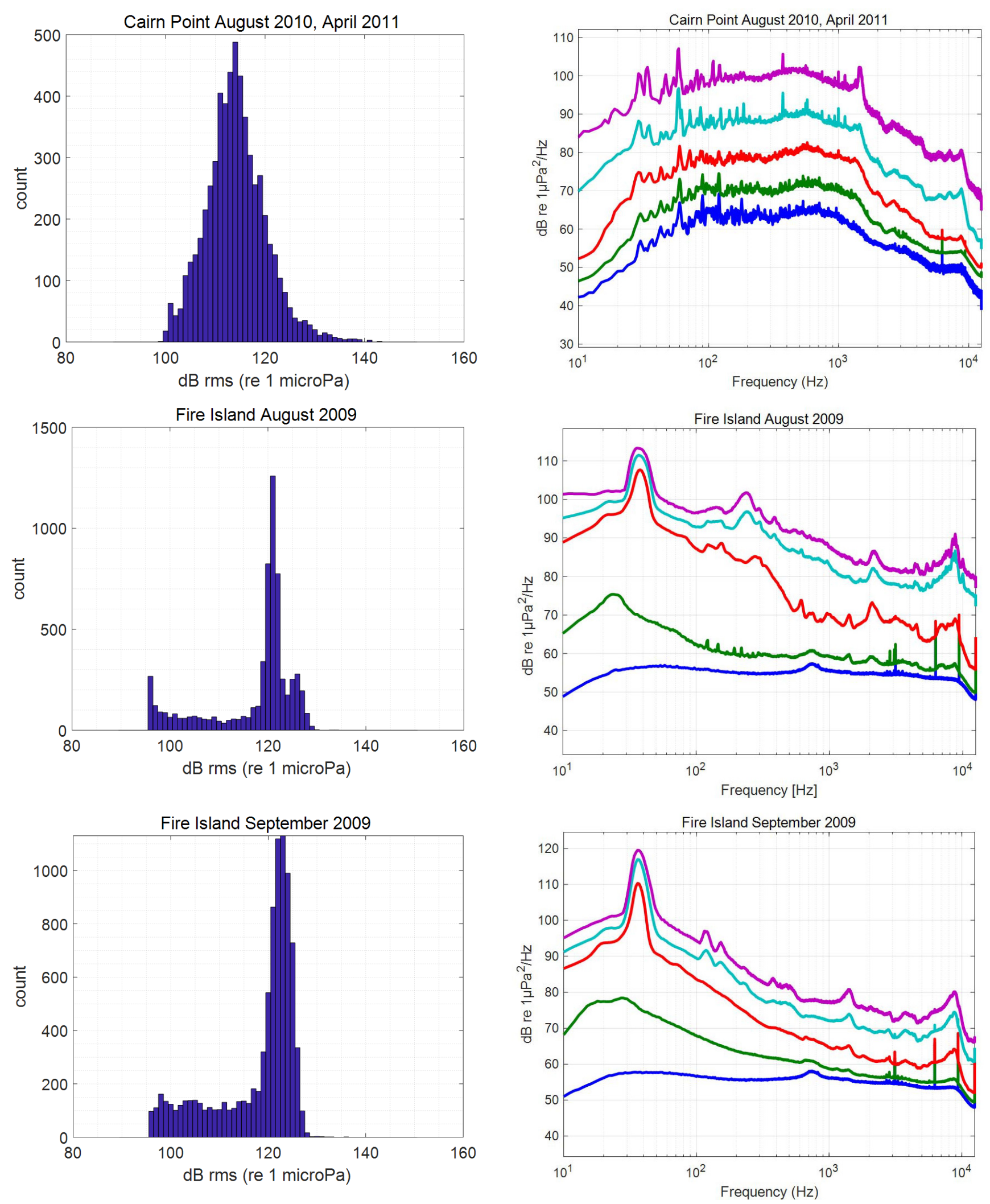

Figure 7.-Continued. 

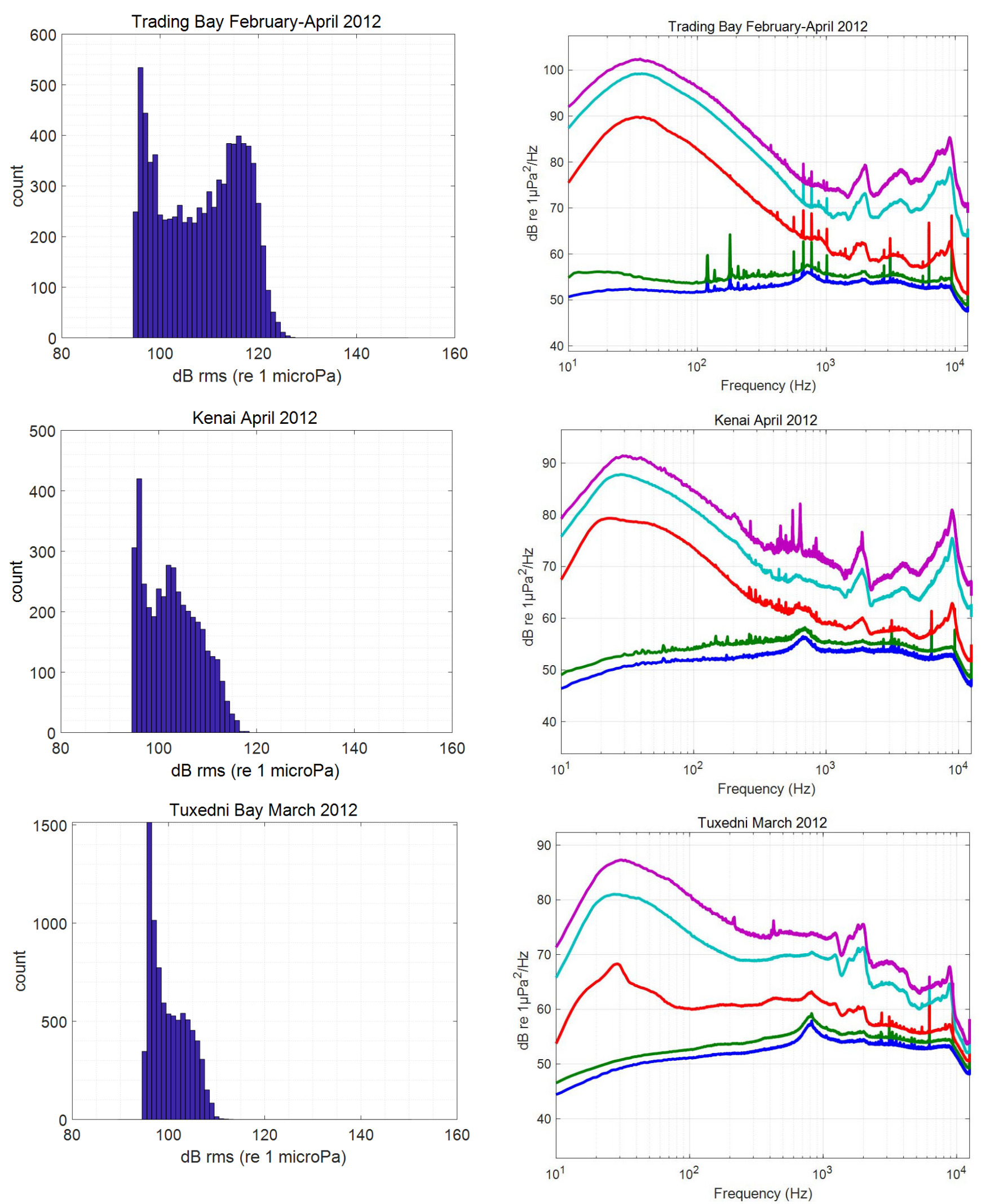

Figure 7.-Continued. 
the exclusion zone coincides with the highest acoustically disturbed area of all the sampled locations in our study.

In the decision process, NMFS considered the small size of the exclusion zone, less than $1 \%$ of the habitat designated, and deemed unlikely that most Department of Defense activities associated with the POA or its operational readiness would require consultation on critical habitat because the activities should not affect that habitat or the identified essential features. Two of these essential features important to the conservation of the Cook Inlet beluga whale were defined as 1) unrestricted passage within or between the critical habitat areas, and 2) the absence of in-water noise at levels resulting in the abandonment of habitat by Cook Inlet beluga whales. Based on a small subsample of the data from Cairn Point, our results highlight the magnitude of the acoustic disturbance in the exclusion zone from activities related to the POA or its operational readiness, including commercial vessel noise (i.e., tugboat and barge operations), dredging noise, pile driving noise, outboard motor noise, as well as all four classes of unidentified noise (unclassified machinery, unidentified clanking or banging, unknown up- or down-sweeps unique to this location, and other unidentified sounds).

Although some of these upper inlet acoustic disturbances have the potential to generate direct impact to Cook Inlet belugas by exceeding injury thresholds, the main concern is the potential for behavioral responses to regulated (e.g., pile driving), regulated but non-mitigated (e.g., dredging), and non-regulated (e.g., shipping) sub-lethal noise exposure levels which occur year-round but at increased levels during the open water season when belugas use this area more intensely.

Beluga spatial displacement in this area of Knik Arm has been hypothesized as one of the explanations for a reduced sighting rate during pile driving seasons (Cornick et al., 2011), reduction in the acoustic detection rate during pile driving activity periods (Saxon Kendall et al., 2013), and on a regular basis due to chronic noise occurrence (Castellote et al. ${ }^{13}$ ). Displacement due to stationary high amplitude noise sources such as pile driving or dredging noise disturbance is a common behavioral reaction in other odontocete species (Tougaard et al., 2009; Pirotta et al., 2013), as well as to construction-related vessel traffic intruding into cetacean habitat (Anderwald et al., 2013), which could lead to long-term abandonment of the disturbed habitat (Morton and Symonds, 2002; Lusseau and Bejder, 2007). For Cook Inlet belugas, spatial displacement due to anthropogenic noise could not be ruled out in a recent study (Small et al., 2017). Therefore, spatial displacement by regulated as well as non-regulated activities might be occurring in this area of the beluga critical habitat.

The lower part of Knik Arm is an important concentration area for belugas (Rugh et al., 2010), as well as a corridor to access major foraging habitat within Knik Arm (Goetz et al., 2012). If belugas are displaced from this area, even if only within the exclusion zone, access to major feeding grounds in the upper sections of the arm could be compromised. With a Recovery Plan highlighting anthropogenic noise as a threat of high concern (NMFS, 2016) and the documented acute and chronic concentration of anthropogenic noise in the lower Knik Arm, potentially negative effects (e.g., displacement, abandonment) from noise exposure in this area should be considered a high research priority.

The amount of unidentified or unclassed recursive noise events, their received levels, and their long durations at Cairn Point, Six Mile, and Trading Bay are relevant and warrant discussion. We presume these events are related to dredging and shipping operations around the port facilities and oil and gas production and related operations in Trading Bay. The identification of their sources and the modes of operation responsible for the emission of these high amplitude events should also be considered a research priority.

Two noise activities were detected that should have been the subject of a permit request; however, they could not be matched with either NMFS or U.S. Army Corps of Engineers permitting files: Specifically, a sub-bottom profile survey and an impact pile driving operation were both detected at Kenai in April 2012. Occurrence of the two unauthorized activities within the relatively small sampled period for this study suggests that activities involving important acoustic disturbances within beluga critical habitat do occur without prior evaluation of their potential impact.

Sub-bottom profiler noise metrics obtained near Fire Island and Kenai highlight that this noise source should be considered an important acoustic disturbance for belugas. The survey in waters around Fire Island was made in August, at the peak of beluga concentration in this important feeding area (Shelden et al., 2015). The survey in Kenai was detected in April, during the only period when this area is visited by belugas on an annual basis (January to April, Castellote et al. ${ }^{8}$ ). Apparently, beluga seasonal distribution was not considered when these surveys were planned, and avoiding disturbing these areas during periods important for belugas would be relatively easy.

Kenai was exposed to intense outboard motor noise in April, which might be related to preparations for the important fishing activities in that area. Our study did not include data from the summer months in Kenai, when most of the commercial, sport, and subsistence fishing occurs, but our April results suggest that outboard motor noise in this area might peak during the summer. This area has historically been intensely used by belugas from April to November (Huntington, 2000), a period when anadromous fish are likely available in high concentrations.

Currently however, beluga appear to prefer February to April for the Kenai river mouth (Castellote et $\mathrm{al}^{8}{ }^{8}$ ), coinciding with the first anadromous fish runs (whitefish, Coregonus sp.; and eulachon); yet, sightings in June, September, and October have also 
been reported (McGuire et al., 2014). Huntington (2000) discussed how the increase in human activity may have affected beluga distribution and abundance in the river and the nearby waters of Kenai. The observed change in beluga seasonality, in particular the absence of belugas during the main summer fishing months (salmon runs), could be related to an increase in human disturbance (i.e., vessel presence and motor noise) during the fishing season. This potential displacement effect merits further research.

\section{Recommendations and Conclusions}

Our results document the high and variable nature of anthropogenic noise disturbance in Cook Inlet beluga critical habitat. Specifically, there is strong variability in source diversity, spatial distribution, and seasonal occurrence of noise, which reflects the many different human activities within the inlet. Some activities clearly deserve further attention, in particular those that in the past were not considered to affect beluga critical habitat or the identified essential features but that might be relevant to the recovery of the Cook Inlet beluga population. In this regard, if a revision of the critical habitat designation were to be considered, the spatial extent of the current exclusion zone and inherent implications for anthropogenic noise management would be warranted.

Commercial shipping is the noise source of highest priority for evaluation due to its reported noise levels, prevalence, and wide spatial distribution throughout the critical habitat. Mitigation of ship noise in other major harbors and ports overlapping with cetacean critical habitat already exists. The best example is at the Vancouver Fraser Port Authority (Canada), within the critical habitat for the endangered southern resident killer whale population. In 2014, the Port Authority launched the Enhancing Cetacean Habitat and Observation (ECHO) Program, designed to better understand and manage the impact of shipping activities on endangered killer whales and other cetaceans throughout the southern coast of British Columbia, and to develop mitigation measures to reduce potential threats. This program and other actions were implemented to characterize and subsequently reduce the acoustic threat from impacts of cumulative vessel noise (Vancouver Fraser Port Authority, 2016).

The area between the POA and Port McKenzie in lower Knik Arm is highly disturbed acoustically due to the convergence of different sources of noise. Because this area is geographically constrained, there is considerable potential for generating a barrier that reduces passage by belugas. A detailed analysis of the activities at the different port facilities in the context of noise production would provide insights on how to minimize this problem, and should include at least the following: 1) avoiding concurrent emission of noise at both the POA and Port McKenzie, 2) evaluating seasonal dredging of the port basin to gain an understanding of the acoustic footprint from different dredge types and under different modes of operation, 3) conducting behavioral observations of belugas to assess their reactions to dredge activities and subsequently define shut down protocols, if necessary, and 4) seasonal scheduling to reduce overlap with beluga peak use of the port basin.

Two important features of the Cook Inlet soundscape highlighted in our study are relevant to current noise management procedures. First, the SPL for natural background noise does not support the current $125 \mathrm{~dB}_{\mathrm{rms}}$ threshold for non-impulsive noise sources. Second, the spatial and temporal overlap of different high amplitude anthropogenic sources of noise, in particular in the Knik Arm area, calls for the implementation of a cumulative impact analysis approach as part of the permitting process. Perhaps a fixed share system for takes (i.e., quota) per season, or a coordinated scheduling and prioritizing of all noise producing activities during the permitting and planning process, could integrate the different activities proposed each season in beluga critical habitat to minimize cumulative impacts.
The Kenai River fishing industry has been largely ignored within the framework of Cook Inlet beluga conservation in part because this activity is seasonal, highly spatially concentrated, and the reduction of prey due to fishing is not of high concern for Cook Inlet beluga recovery (NMFS, 2016). However, the footprint of acoustic and physical disturbance at the mouth of Kenai River could be considerable and overlaps with the historical occurrence of belugas in this river. Determining whether belugas have been displaced by fishing activities from this previously important feeding area should be considered a management priority.

Our results suggest that the amount of unidentified or unclassed but repetitive anthropogenic noise warrants special consideration to identify those sources that might require further regulatory control. Concentrated oil and gas production in the Trading Bay field and shipping activity at the port facilities in lower Knik Arm deserve a closer look in this regard.

The detection of unpermitted actions, such as pile driving or sub-bottom profiling operations in the Kenai river mouth area, suggest that authorities should strengthen enforcement and outreach efforts to reduce the negative impact of underwater noise on the recovery of the beluga population. For example, the development of underwater noise reduction incentive programs could be considered for different industries, such as the multiple programs in place for airports, or the recently started program for the Port of Vancouver, Can. Also, further acoustic monitoring in areas where human activities occur or are expected should be supported as it would help understand the scope of this problem.

Much work remains to understand and reduce the acoustic impact to Cook Inlet belugas. Many sources of noise remain unidentified that may be relevant contributors to the disturbance of the critical habitat soundscape. Other noise sources are now known but have typically been excluded from control and regulation, in part because of the inconvenience and lack of quan- 
tified measurements. Acute noise-producing activities such as pile driving or oil and gas exploration are subject to strict noise impact evaluations and include marine mammal monitoring and mitigation programs; however, the spatial or temporal accumulation of noise from other sources, and the concurrent exposure to other stressors, are not considered.

Clearly, Cook Inlet waters host a high concentration of human activities that is reflected in the magnitude of noise disturbance documented in this study. The management and research recommendations presented here are consistent with many of the recovery actions proposed in the recovery plan (NMFS, 2016), and represent a first urgent step towards understanding the effects of anthropogenic noise on the endangered Cook Inlet beluga population, and how to manage those effects to promote beluga recovery.

\section{Acknowledgments}

This study would have not been possible without the collective effort from the rest of team CIBA which includes Justin Jenniges, Alaska Department of Fish and Game and Shannon Atkinson, University of Alaska Fairbanks. Christopher Garner, Joint Base Elmendorf Richardson, provided critical logistic support during field work in Knik Arm and reviewed the text related to military activities. Dave McKay provided excellent service for the deployment and recovery of acoustic moorings. Steve Ribuffo, director of the Port of Anchorage, provided ship recall log data to help classifying noise events and provided useful comments on the shipping activity at the Port of Anchorage. Julie Anderson, U.S. Army Corps of Engineers, provided dredging activity details at the Port of Anchorage to help classifying noise events. Peter Garay, marine pilot at Southwest Alaska Pilots Association, provided useful comments on shipping behavior in Cook Inlet.

Brian Marston, Northern Kenai Peninsula Area manager for the Alaska Department of Fish and Game, provided details on the fishery activities at the mouth of Kenai River. Barbara Mahoney, NMFS Alaska Regional Office, provided details on the pile driving and sub-bottom profiling surveys permitted in Cook Inlet. Rod Hobbs (retired), Marine Mammal Laboratory, Alaska Fisheries Science Center, reviewed an earlier version of this paper. Christine Schamle and John Skinner, Alaska Department of Fish and Game, prepared earlier versions of the figures presented in this paper. This publication was partially funded by the Joint Institute for the Study of Atmosphere and Ocean (JISAO) under NOAA Cooperative Agreement NA15OAR4320063 (2015-2020). Use of trade names or commercial firms does not imply endorsement by the National Marine Fisheries Service, NOAA.

\section{Literature Cited}

ADFG. 2015. Alaska sport fishing survey. Alaska Dep. Fish Game, Div. Sport. Fish., Juneau. (Avail. online at https://www.adfg.alaska.gov/ sf/sportfishingsurvey/index.cfm?ADFG=area. results).

Anderwald, P., A. Brandecker, M. Coleman, C. Collins, H. Denniston, M. D. Haberlin, M. O’Donovan, R. Pinfield, F. Visser, and L. Walshe. 2013. Displacement responses of a mysticete, an odontocete, and a phocid seal to construction-related vessel traffic. Endang. Species Res. 21:231-240.

Awbrey, F. T., J. A. Thomas, and R. A. Kastelein. 1988. Low-frequency underwater hearing sensitivity in belugas, Delphinapterus leucas. J. Acoust. Soc. Amer. 84:2,273-2,275.

Austin, M., S. Denes, J. MacDonnell, and G. Warner. 2016. Hydroacoustic monitoring report: Anchorage Port Modernization Project Test Pile Program. Version 3.0. Tech. Rep. by JASCO Appl. Sci., Halifax, Can., 215 p. (Avail. online at https://www.portofalaska.com/wp-content/uploads/APMP-TPP_ Kiewit-Final-Report.pdf).

Barclay, D. R., and M. J. Buckingham. 2014. On the spatial properties of ambient noise in the Tonga Trench, including effects of bathymetric shadowing. J. Acoust. Soc. Am. 136(5):2,497-2,511.

Bassett, C., J. Thomson, P. H. Dahl, and B. Polagye 2014. Flow-noise and turbulence in two tidal channels J. Acoust. Soc. Am. $135: 1,764-1,774$.

Bejder, L., A. Samuels, H. Whitehead, H. Finn, and S. Allen. 2009. Impact assessment research: use and misuse of habituation, sensitisation and tolerance in describing wildlife responses to anthropogenic stimuli. Mar. Ecol. Prog. Ser. 395:177-185.

Burgess, W. C. 2014. Ambient underwater sound levels measured at Windy Corner, Turnagain Arm, Alaska. Greeneridge Sci., Inc., Rep. 515-2, 18 p. (Avail. online at www.windycorner.info/projects/windycorner/documents/ beluga_noise_study.pdf).
Castellote, M., T. A. Mooney, L. Quakenbush, R. Hobbs, C. Goertz, and E. Gaglione. 2014. Baseline hearing abilities and variability in wild beluga whales (Delphinapterus leucas). J. Exp. Biol. 217:1,682-1,691.

R. J. Small, M. O. Lammers, J. Jenniges, J. Mondragon, and S. Atkinson. 2016. Dual instrument passive acoustic monitoring of belugas in Cook Inlet, Alaska. J. Acoust. Soc. Am. 139(5):2,697-2,707.

COSEWIC (Committee on the Status of Endangered Wildlife in Canada). 2014. Summary of COSEWIC Wildlife Species Assessments, Nov. 2014. (Avail. online at www.cosewic. gc.ca/rpts/Full_List_Species_Nov_2014_e. pdf).

Cornick, L., S. Love, L. Pinney, C. Smith, and Z. Zartler. 2011. Distribution, habitat use and behavior of Cook Inlet beluga whales and other marine mammals at the Port of Anchorage marine terminal redevelopment project, June-November 2011. Sci. Mar. Mammal Monitoring Prog. 2011 Annual Rep. Alaska Pacific Univ., Dep. Environ. Sci., 55 p. (Avail. online at https://alaskafisheries.noaa.gov/ sites/default/files/2011 poammannualrpt.pdf).

Dahl, P. H., C. A. F. de Jong, and A. N. Popper. 2015. The underwater sound field from impact pile driving and its potential effects on marine life. Acous. Today 11(2):18-25.

Erbe, C. 2008. Critical ratios of beluga whales (Delphinapterus leucas) and masked signal duration. J. Acoust. Soc. Am. 124(4):2,216-2,223.

C. Reichmuth, K. Cunningham, K. Lucke, and R. Dooling. 2016. Communication masking in marine mammals: A review and research strategy. Mar. Poll. Bull. 103:15-38.

Ezer, T., R. C. Hobbs, and L. Y. Oey. 2008. On the movement of beluga whales in Cook Inlet, Alaska. Oceanography 21:186-196.

Finneran, J. J. C. E. Schlundt, D. A. Carder, and S. H. Ridgway. 2002. Auditory filter shapes for the bottlenose dolphin (Tursiops truncatus) and the white whale (Delphinapterus leucas) derived with notched noise. J. Acoust. Soc. Am. 112 (1):322-328.

Gervaise, C., Y. Simard, and N. Roy. 2012. Shipping noise in whale habitat: characteristics, sources, budget, and impact on belugas in Saguenay-St. Lawrence Marine Park hub. J. Acoust. Soc. Am. 132(1):76-89.

Goetz, K. T., R. A. Montgomery, J. M. Ver Hoef, R. C. Hobbs, and D. S. Johnson. 2012. Identifying essential summer habitats of the endangered beluga whale Delphinapterus leucas in Cook Inlet, Alaska. Endangered Species Res. $16: 135 \mathrm{e} 147$

Greene, C. R., Jr., M. W. McLennan, R. G. Norman, T. L. McDonald, R. S. Jakubczak and W. J. Richardson. 2004. Directional frequency and recording (DIFAR) sensors in seafloor recorders to locate calling bowhead whales during their fall migration. J. Acoust. Soc. Am. 116(2):799-813.

Heenehan, H. 2009. Fort Richardson ordnance detonations and the harbor porpoise: a case study in marine mammal bioacoustics. Honors scholar thesis. Univ. Conn., Storrs, CT, 53 p. (Avail. online at http://opencommons. uconn.edu/srhonors theses/108/).

Hobbs, R. C., C. L. Sims, K. E. W. Shelden, L. Vate Brattström, and D. J. Rugh. 2015. Annual calf indices for beluga whales (Delphinapterus leucas) in Cook Inlet, Alaska, 
2006-2012. Mar. Fish. Rev. 77(2):40-58. (doi: https://doi.org/10.7755/MFR.77.2.3).

Hoffman, C. A. 2012. Mitigating impacts of underwater noise from dredging on beluga whales in Cook Inlet, Alaska. In A. N. Popper and A. Hawkins (Editors), The effects of noise on aquatic life. Adv. Exper. Medi. Biol. 730:617-620.

Huntington, H. P. 2000. Traditional knowledge of the ecology of the belugas, Delphinapterus leucas, in Cook Inlet, Alaska. Mar. Fish. Rev. 62(3): 134-140

Johnson, C. S., M. W. McManus, and D. Skaar. 1989. Masked tonal hearing thresholds in the beluga whale. J. Acoust. Soc. Am. $85(6): 2,651-2,654$

Klishin, V. O., V. V. Popov, A. Y. Supin. 2000. Hearing capabilities of a beluga whale, Delphinapterus leucas. Aquat. Mamm. 26:212-228.

Lammers, M. O., M. Castellote, R. J. Small, S. Atkinson, J. Jenniges, A. Rosinski, J. Oswald, and C. Garner. 2013. Passive acoustic monitoring of Cook Inlet beluga whales (Delphinapterus leucas). J. Acoust. Soc. Am. 134(3):2,497-2,504.

Lusseau, D., and L. Bejder. 2007. The long-term consequences of short-term responses to disturbance experiences from whalewatching impact assessment. Int. J. Comp. Psychol. 20:228-236

Madsen, P. T. 2005. Marine mammals and noise: Problems with root mean square sound pressure levels for transients. J. Acoust. Soc. Am. 117:3,952-3,957.

Malme, C. I., P. R. Miles, C. W. Clark, P. Tyack, and J. E. Bird. 1983. Investigations of the potential effects of underwater noise from petroleum industry activities on migrating gray whale behavior. Bolt Beranek Newman, Inc., Rep. 5366, 65 p. and 1984 Investigations of the potential effects of underwater noise from petroleum activities on migrating gray whale behavior. Phase II: January 1984 migration. Contr. 14-12-000129033, Bolt Beranek Newman Inc., Rep. 5586,358 p.

McGuire, T., A. Stephens, and L. Bisson. 2014. Photo-identification of Cook Inlet beluga whales in the waters of the $\mathrm{Ke}$ nai Peninsula borough, Alaska. Final Rep. of Field Activities and Belugas Identified 2011-2013. Rep. prep. by LGL Alaska Res.
Assoc., Inc., Anchorage, Alaska, for the Kenai Peninsula borough, 92 p. (Avail. online at https://www.cookinletbelugas.com/ reports-and-publications).

Menze, S., D. P. Zitterbart, I. van Opzeeland, and O. Boebel. 2017. The influence of sea ice, wind speed and marine mammals on Southern Ocean ambient sound. R. Soc. Open. Sci. 4:160370.

Morton, A. B., and H. K. Symonds. 2002. Displacement of Orcinus orca (L.) by high amplitude sound in British Columbia, Canada. ICES J. Mar. Sci. 59:71-80. (doi: https://doi. org/10.1006/jmsc.2001.113).

NMFS. 2008. Conservation plan for the Cook Inlet beluga whale (Delphinapterus leucas). U.S. Dep. Commer., NOAA. Natl. Mar. Fish. Serv., Alaska Reg., Protected Resour. Div., Juneau, Alaska. (Avail. online at https:// alaskafisheries.noaa.gov/sites/default/files/ cp2008.pdf).

2016. Recovery plan for the Cook Inlet beluga whale (Delphinapterus leucas). U.S. Dep. Commer., NOAA. Natl. Mar. Fish. Serv., Alaska Reg., Protected Resour. Div., Juneau, Alaska. (Avail. online at https://alaskafisheries.noaa.gov/sites/default/files/cib_recovery_plan_final.pdf).

2018. Revisions to: Technical guidance for assessing the effects of anthropogenic sound on marine mammal hearing (Version 2.0): Underwater thresholds for onset of permanent and temporary threshold shifts. U.S. Dep. Commer., NOAA Tech. Memo. NMFS-OPR-59, 167 p. (Online at https://www.fisheries.noaa.gov/webdam/ download/75962998)

NOAA. 1995. Small takes of marine mammals incidental to specified activities; offshore seismic activities in Southern California. 60 Fed. Regist. 53753 (17 Oct. 1995), p. 53,75353,760. (Online at https://www.federalregister.gov/d/2014-05158/page-13626). 2011. Endangered and threatened species: designation of critical habitat for Cook Inlet beluga whale. 76 Fed. Regist. 20180 (11 April 2011), p. 20,180-20,214. (Online at https://www.federalregister. gov/d/2011-8361).

Pirotta, E., B. E. Laesser, A. Hardaker, N. Riddoch, M. Marcoux, and D. Lusseau. 2013. Dredging displaces bottlenose dolphins from an urbanised foraging patch. Mar. Pollut. Bull. 74:396-402.
Richardson, W. J., C. R. Greene, Jr., C. I. Malme, and D. H. Thomson. 1995. Marine mammals and noise. Acad. Press, Inc., San Diego, Calif., 576 p.

Rolland, R. M., S. E. Parks, K. E. Hunt, M. Castellote, P. J. Corkeron, D. P. Nowacek, S. K. Wasser, and S. D. Kraus. 2012. Evidence that ship noise increases stress in right whales. Proc. R. Soc. Edinb. Biol. 279:2,363-2,368.

Rugh, D. J., K. E. W. Shelden, and R. C. Hobbs. 2010. Range contraction in a beluga whale population. Endangered Species Res. 12:69-75.

Saxon Kendall, L., A. Širović, and E. H. Roth. 2013. Effects of construction noise on the Cook Inlet beluga whale (Delphinapterus leucas) vocal behavior. Can. Acoust. 41(3):1-13.

Scientific Fishery Systems. 2009. Port of Anchorage marine terminal development project 2008. Underwater noise survey during construction pile driving. PO Box 242065. Anchorage, Alaska 99524, 231 p. (Avail. online at https://alaskafisheries.noaa.gov/sites/default/files/2008underwtrnoise piledrive.pdf).

Shelden, K. E. W., K. T. Goetz, D. J. Rugh, et al. 2015. Spatio-temporal changes in Beluga Whale, Delphinapterus leucas, distribution: results from aerial surveys (1977-2014), opportunistic sightings (1975-2014), and satellite tagging (1999-2003) in Cook Inlet, Alaska. Mar. Fish. Rev. 77(2):1-109.

Small, R. J., B. Brost, M. Hooten, M. Castellote, and J. Mondragon. 2017. Potential for spatia displacement of Cook Inlet beluga whales by anthropogenic noise in critical habitat. Endang. Species Res. 32:43-57.

Tougaard, J., J. Carstensen, and J. Teilmann. 2009. Pile driving zone of responsiveness extends beyond $20 \mathrm{~km}$ for harbour porpoises (Phocoena phocoena (L.)). J. Acoust. Soc. Am. 126:11-14

Vancouver Fraser Port Authority. 2016. Enhancing cetacean habitat and Observation (ECHO) Program. 2015 Annual Report, 17 p. (Avail. online at http://www.portvancouver.com/wp-content/uploads/2016/05/ECHOProgram-Annual-Report-2015-FINAL.pdf).

Wright, F. F., G. D. Sharma, and D. C. Burbank 1973. ERTS-1 observations of sea surface circulation and sediment transport, Cook Inlet, Alaska: Symposium on Significant Results obtained from the Earth Resources Technology Satellite-1, NASA SP-327, p. 1315-1322. (Avail. online at https://ntrs.nasa.gov/search. jsp? $R=19730019615$ ). 